\title{
وسائل اعمال حق تقرير المصير ونماذج ممارستها في ظل التطور ات الدولية المعاصرة
}

أ.م.د. أز هار عبداله حسن الحيالي(*)

ملخص:

تحظى وسائل اعمال حق تقرير المصير بابعادها السلمية وغير السلمية والمزوجة

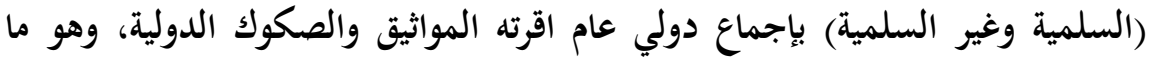
جعل لها أبعاد متنوعة على المستوى التطبيقي خاصة في ظل التطورات الدولية المعاصرة

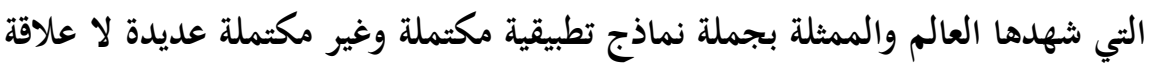
لها بنظرية حق تقرير المصير المرتبطة بتحرير الشعوب من الهيمنة الإستعمارية أو بتحرير القوميات المضطهدة. الكلمات المفتاحية:( تقرير المصير، وسائل تقرير المصير، نماذج ممارسة تقرير المصير) المقدمة :

ان الشعوب كافة تناضل من أجل حقوقها وتسعى الى تغيير أحوالها بكل الوسائل المتاحة فحسب طبيعتها ومكوناتها الداخلية التي تتسم بالاختلاف والتنوع الاثني والقومي تسعى الى استمرار وحدة كيانها السياسي والجغرافي الذين الته عبر تضحيات جسام لتقرير مصيرها بالاستقلال عن المستعمر واقامة نظامها السياسي الذي تراسي تراه مناسياً

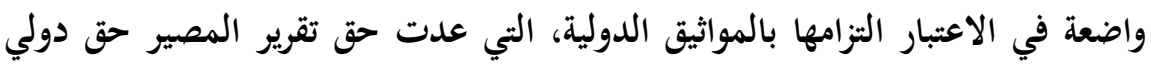

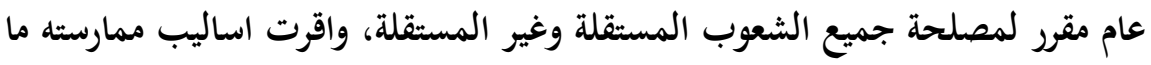
بين وسائل ذات طابع سلمي تتمثل باقامة الاحزاب السياسية والجمعيات الثقافية 
والتنظيمات المدافعة عن مطالبها ويغلب على ممارساتها الحوار والمشاركة في الحياة السياسية للاستجابة لمطالبها، في المقابل هناك وسائل ذات طابع غير سلمي تتمثل باساليب القوة للتعبير عن مقاومة السلطة والنظام السياسي وتاكيد الرغبة في الاستقلال، بيد ان نجاحها يعتمد بشكل اساسي على الدعم والمساندة الخارجية بمختلف اشكالها لتعزيز مواقف الانفصال ولعل نموذج اقليم كوسوفو يطرح ضمن هذا الخيار. ومن هنا لتهن تنبع اهمية البحث الذي يسلط الضوء على اعمال حق تقرير المصير النظرية في تحقيق

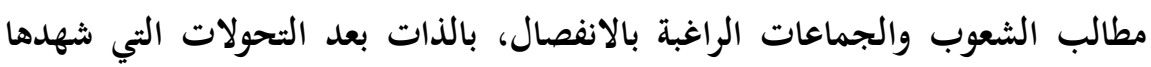

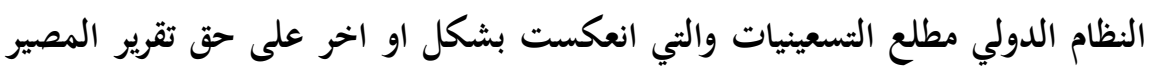

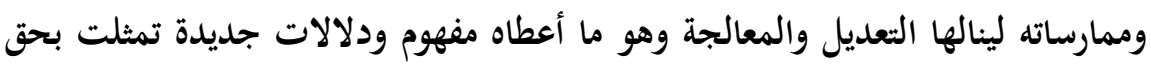
تقرير المصير القومي الذي ادخل الدول في عصر انقسامات لا محدودة أرتكن خحلالها

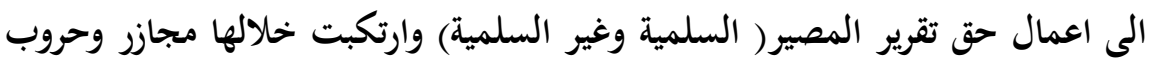

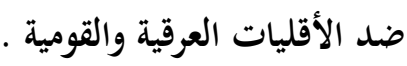
وتتمثل اشكالية البحث في ان اعمال حق تقرير المصير التي تعطي الشعوب والامم ان

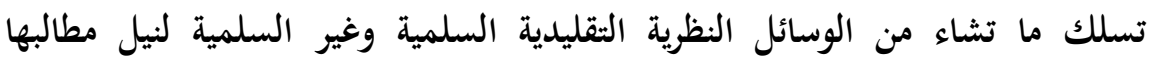
بالانفصال، او الجمع بين الوسيلتين في حالات عدة مع توظيفها لعناصر الدعم

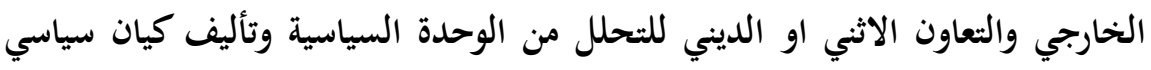
خاص بها، لم تستخدم بروية وحكمة من قبل الجماعات العرقية والقومية، وهو ما كانت له ابعاد خطيرة على جميع الدول خاصة التي تضم بنية طائفية وعرقية واثنية متعددة وقد لهد تم ذلك باسم حق تقرير المصير. اما فرضية البحث فمفادها ان التحولات التي شهدها المجتمع الدولي على مختلف المعير الصعد وتطور القانون الدولي المعاصر، وبروز المعاهدات والمواثيق واعلان حقوق تهري الإنسانوان انعكست بشكل او اخر على مفهوم حق تقرير المصير ودلالاته التي اقرتها المواثيق والاعلانات الدولية واكدتها التجارب الدولية للمجتمع الدولي، الا ان اساليب لهري ممارسته من قبل الشعوب والجماعات القومية والعرقية في تحقيق اهدافها ظلت تتراوح 
بين وسائل سلمية وغير سلمية واخرى تجمع بينهما بتناوب والثدرج في الاستخدام تبعا

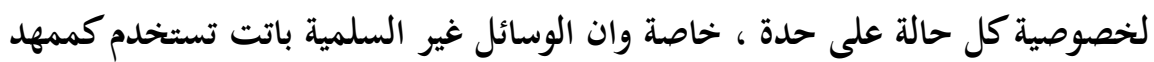
للانتقال للوسيلة السلمية وتحقيق مطلب الانفصال.

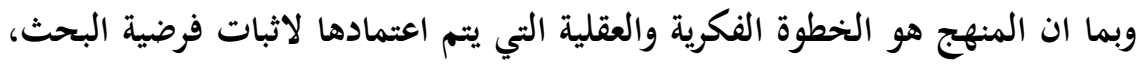
فقد ارتأينا اعتماد المنهج التحليلي المتعدد المقتربات للإحاطة بالجوانب النظرية والتطبيقية لاعمال حق تقرير المصير مع الاستعانة بالمنهج المقارن في استقراء واقع

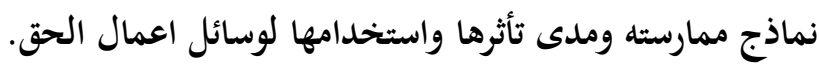
واقتضت هيكلية البحث تقسيمه فضلاً عن المقدمة إلى مبحثين، تناول المبحث الأول: وسائل اعمال حق تقرير المصير، وتضمن مطلبين: تناول المطلب الاول: الوسائل السلمية (الودية والديمقراطية)، وتناول المطلب الثاني: الوسائل غير السلمية (استخدام

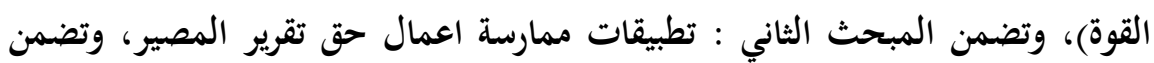
مطلبين: تناول المطلب الاول : التطبيقات السلمية، وتناول المطلب الثاني : التطبيقات

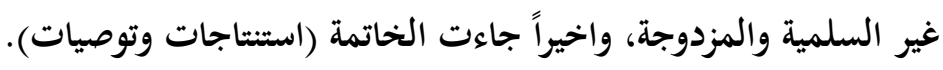
المبحث الاول: وسائل اعمال حق تقرير المصير منحت الشعوب الحق في تقرير مصيرها من خلال الوسائل السلمية، وفي حال عدم جدواها يتم اللجوء الى استخدام القوة لتقرير مصيرها، وهكذا حظيت هذه الوسائل بالمشروعية، وفقا لتجربة الامم المتحدة. وهو ما سنتناوله كالاتي المطلب الاول: الوسائل السلمية(الودية والديمقراطية): تحظى هذه الوسيلة بإجماع غالبية اعضاء الأمم المتحدة في ممارسة حق تقرير المصير،

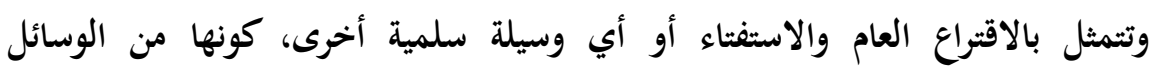

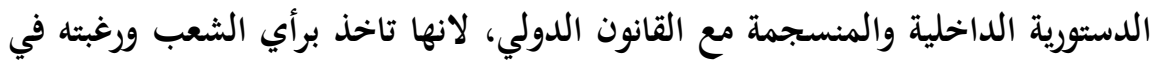
تقرير المصير من خلال التصويت المباشر، وهذا ما أكدته الجمعية العامة في قرارها

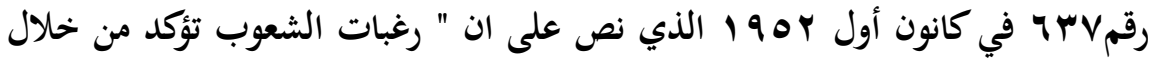


الاقتراع العام أو أية وسائل ديمقراطية أخرى و معترف بها، ويفضل أن تمارس تحت إشراف الأمم المتحدة "(1). ويلاحظ ان الاستفتاء او الاقتراع العام من افضل الوسائل التي عرفت في تقرير مصير حتى الان، فالاستفتاء من الناحية اللغوية يراد به طلب الفتوى او الراي او الحكم في

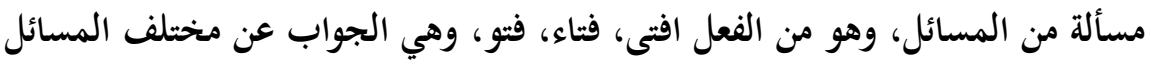
الشرعية والقانونية(").كما ورد مصطلح الاستفتاء في القران الكريم في مواضع متعددة منها: سورة النساء / الاية I TV بقوله تعالى " ويستفتونك في النساء قل الله يفتيكم فيهن " وسورة الكهف / الاية r بقوله تعالى" سيقولون ثلثة رابعهم كلبهم ويقولون خمسة سادسهم كلبهم رجما بالغيب ويقولون سبعة وثامنهم كلبهم قل ربي اعلم بعدتهم

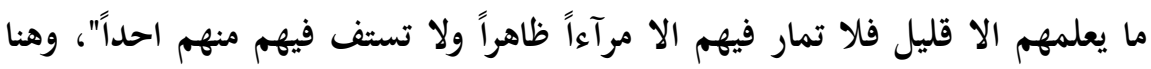

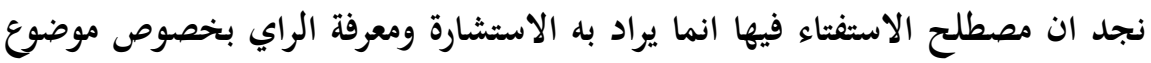
(")

اما اصطلاحاً فيراد به " الرجوع الى الشعب لاخذ رأيه بالموافقة او بالرفض في أي

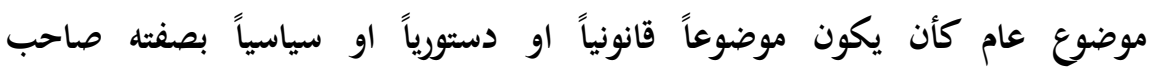

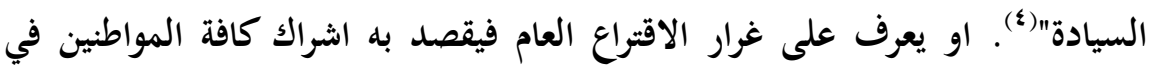
التصويت على موضوعه دون اشتراط قسط تعليمي او نصاب مالي او انتماء وراثي (0). وهنا فان مفهوم الاستفتاء يتسع ليشمل كل موضوع عام بغض النظر عن طبيعته(دستوريا

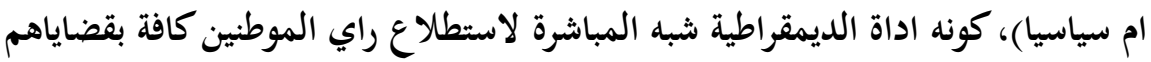

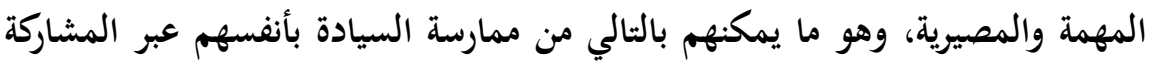

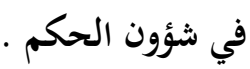
وهناك من يعرف الاستفتاء في ضوء الموضوع المستفتى عليه فيرى بانه " أخذ رأي الشعب في أمر من الأمور فإن كان هذا الامر مشروع قانون سمي الاستفتاء شرعياً وان

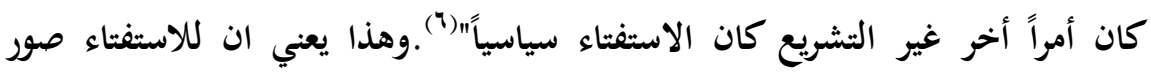
تختلف باختلاف الموضوع المستفنى عليه . 
اما المفهوم السياسي للاستفتاء فيراد به استطلاع راي الشعب بشأن تولي شخص معين

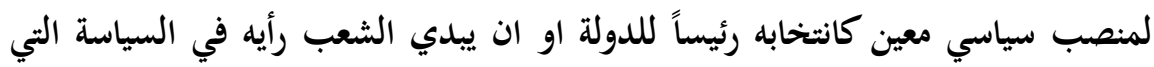

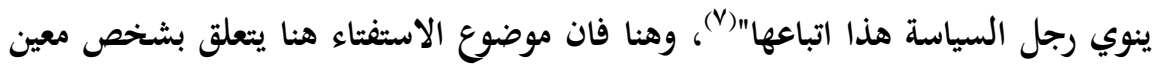
او موضوع يطرحه كان يكون مشروع دستور او قرار سياسي او امرا من امور السياسة

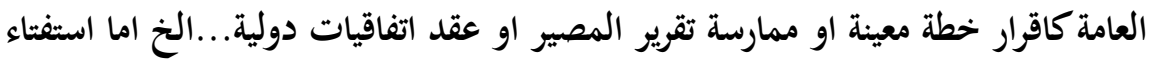
تقرير المصير موضوع بحثنا فمحله هو اخذ راي الشعب وتخييره بين الانفصال والتبعية لدولة ما او بالاتحاد معها. اما الاقتراع العام فهو نظام قانوني بموجبه يشترك افراد الشعب كافة في الانتخابات دون وضع قيد او شرط ودون ان يخل ذلك ببعض الشروط التنظيمة ذات الطابع القانوني

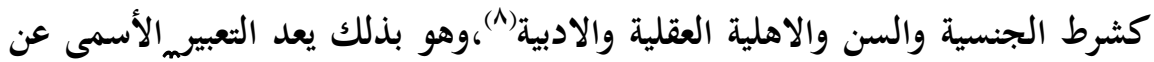

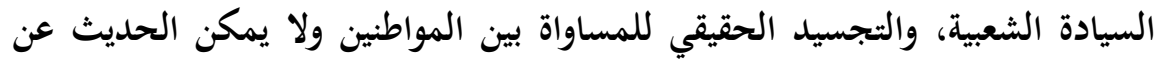

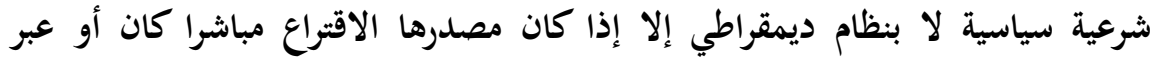

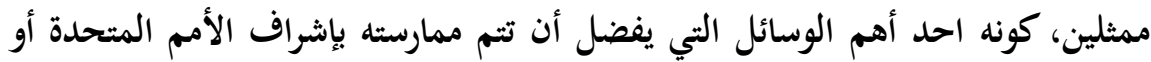

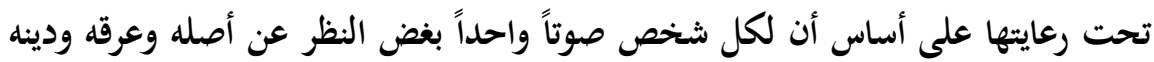

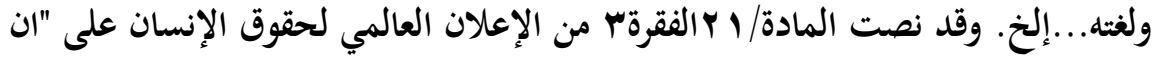
إرادة الشعب هي مصدر سلطة الحكومة، ويعبر عن هذه الإرادة بانتخابات نزيهة دورية تجري على أساس الاقتراع السري وعلى قدم المساواة بين الجميع او حسب أي إجراء

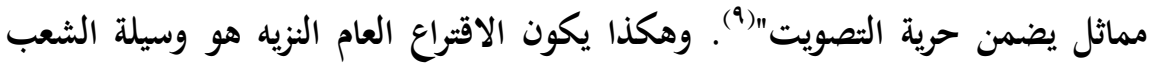
لتقرير مصيره وضمان وجود نظام ديمقراطي. عموماً، يعد الاستفتاء والاقتراع العام من الوسائل السلمية والديمقراطية المهمة، التي تعطي للشعب حق إبداء رأيه ورسم المنهج السياسي لدولثه،بما في ذلك حقها في تقرير المصير او الفصل في بعض الاشياء في ظل وجود برلمان من خلال انظمة الحكم

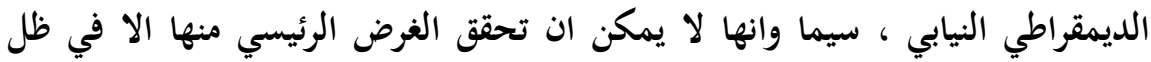

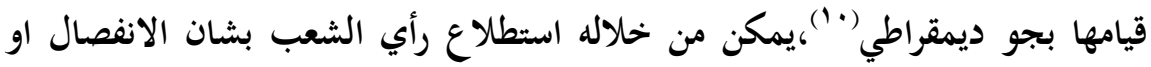


البقاء، وهنا تتجلى قيمته الحقيقية حين يفهم الموضوع المستفتى من قبل كل من يدلي

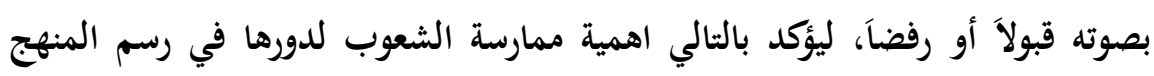

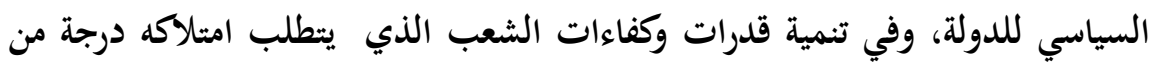
الوعي السياسي. كما تتضمن الوسائل السلمية لتحقيق اهداف الانفصال أقامة الجمعيات والتنظيمات الثقافية ومنظمات المجتمع المدني للدفاع عن حقوق ومبادئ الجماعات القومية والعرقية من ناحية، وانشاء الاحزاب السياسية للمشاركة في الحياة الاجتماعية والسياسية وفي العمليات الانتخابية والتنموية من ناحية اخرى، والتي تعد من اهم الوسائل السلمية للحد من الاحساس بالتهميش (1'). وهنا تثار التساؤلات حول طبيعة الحالات التي من خلالها يحق للشعوب استخدام الوسيلة الديمقراطية والظروف المناسبة؟ وما هي طبيعة الوضع في حال انكار السلطة الستة المركزية حق الشعب في تقرير مصير ورفضها السماح بتطبيق الوسائل الديمقراطية؟ وتقتضي الاجابة هنا الاشارة الى ان ظهور النظام الديمقراطي النيابي القائم على التعددية

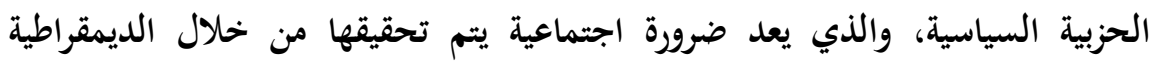

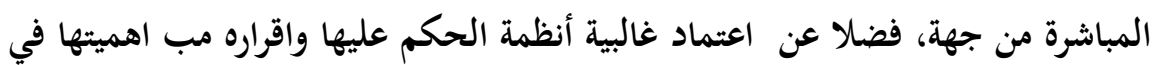
دساتيرهم من جهة اخرى، فرض الرجوع الى الشعب في بعض الأمور لتصبح هذه

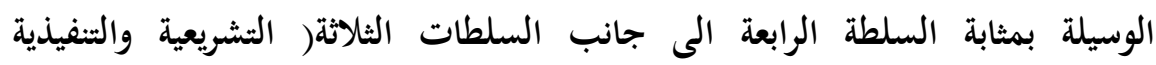

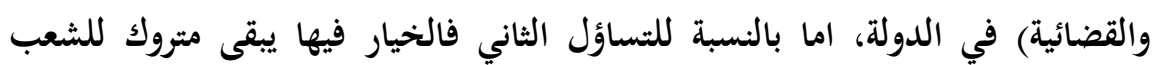
نفسه اما الرضوخ والاذعان او اللجوء إلى القوة من اجل تحقيق مطالبه. المطلب الثاني: الوسائل غير السلمية (استخدام القوة)

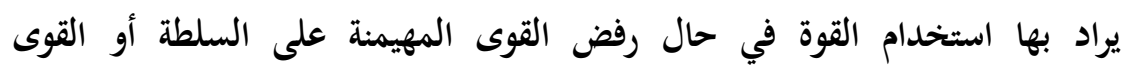
الاستعمارية وأنكارها لحق الشعب في تقرير مصيره، فإن لهذا الشعب أن يمارسه بالكفاح

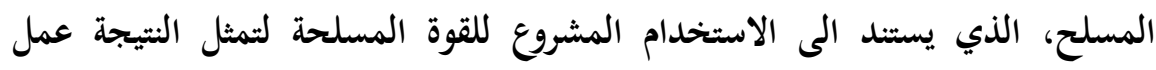
عسكري شعبي مشروع لمقاومة محتل او مغتصب للسلطة، وبهذه الصيغة نالت معظم 
شعوب العالم استقلالها ومارست سيادتها دون قيود بعد إنتهاء الحرب العالمية الثانية وواجهت الدول الاستعمارية مقاومة عنيفة.

وهنا يثار التساؤل حول مشروعية حركات التحرر لنيل حق تقرير المصير؟ الاجابة عليه

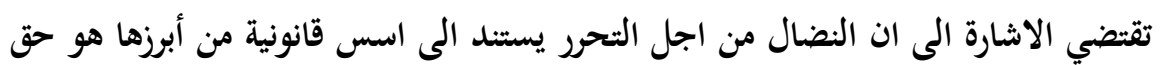
الدفاع الشرعي عن النفس، حيث اكدت المادة 51من ميثاق الأمم المتحدة هذا الحق

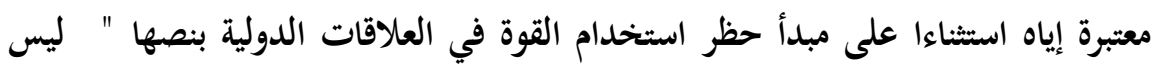

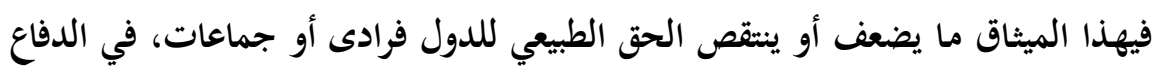

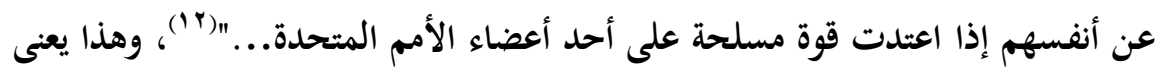
ان ميثاق الامم المتحدة ليس فيه ما يحول دون حق الدول في الدفاع عن نفسها.

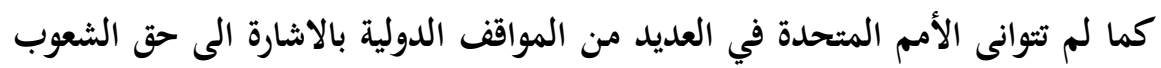

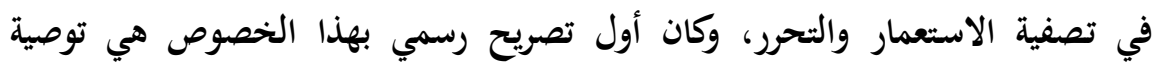

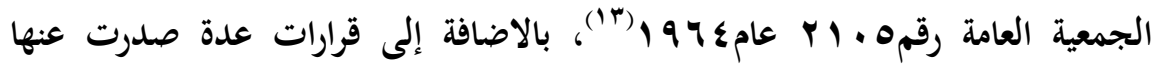

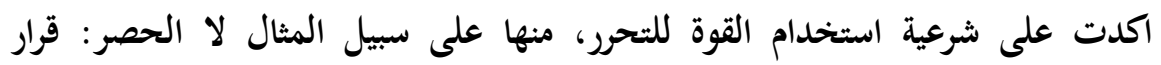

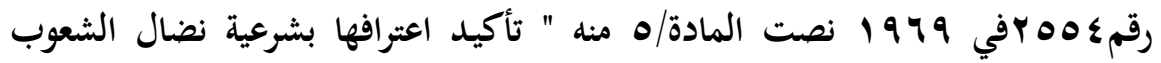

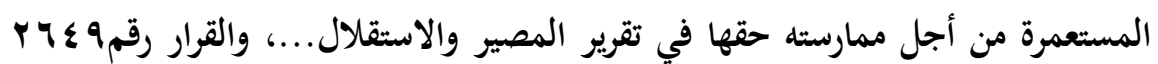
في عام I IV " " تعترف فيه الجمعية العامة بشرعية كفاح الشعوب الخاضعة للسيطرة

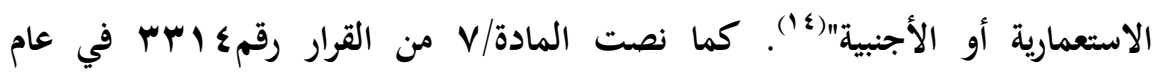
•9V الخاصة بتعريف العدوان على الاعتراف بحق الشعوب المستعمرة في استعمال

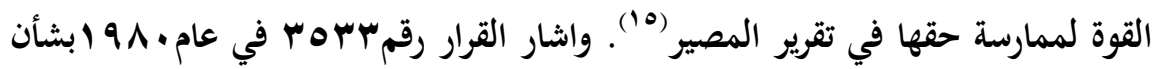
تقرير المصير في الفقرة الثانية" تأكيد شرعية كفاح الشعوب في سبيل الاستقلال والسلامة

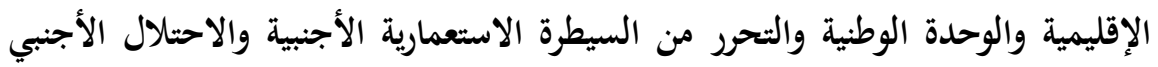

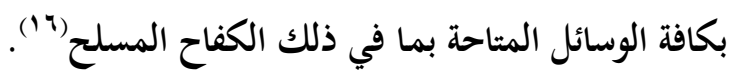


بالاضافة الى قرارات اخرى اعتمدتها المنظمة الدولية بإجماع شبه كامل، منها قرار

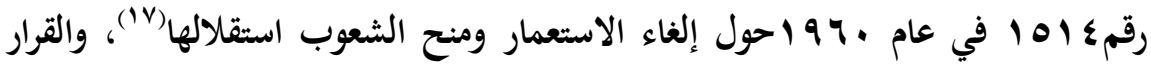

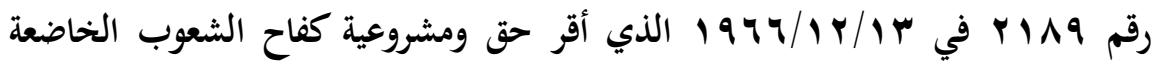

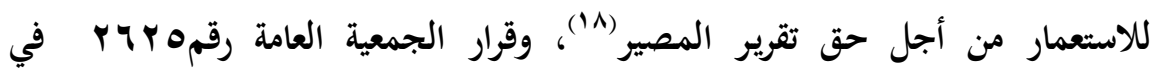

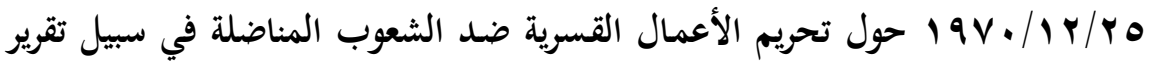

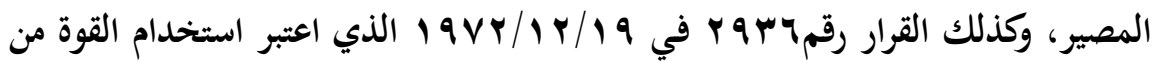

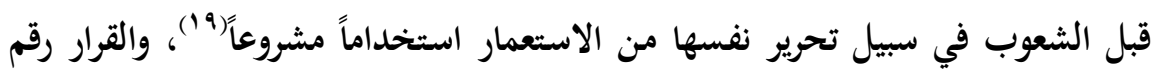

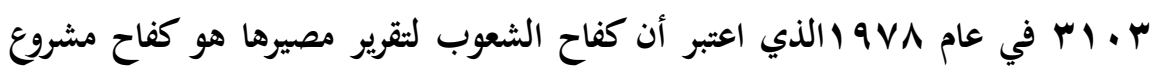

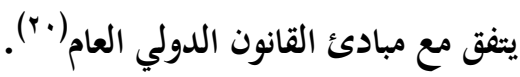

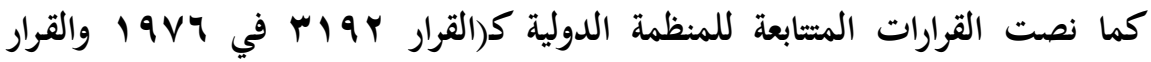

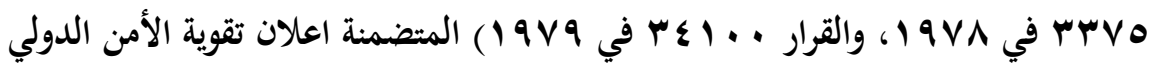

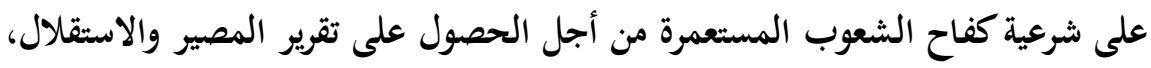

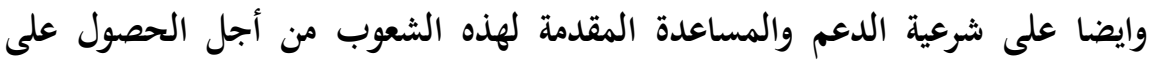

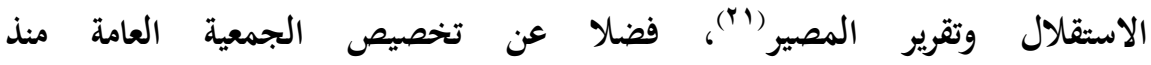
عامبح الفقرة/ץ من توصياتها السنوية التي تصدرها بخصوص" أهمية التحقيق العالمي لحق الشعوب في تقرير الدصير والتسريع في احترام الإنسان"، للتأكيد على الكفاح

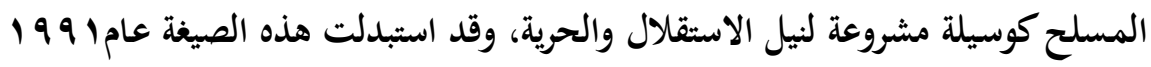

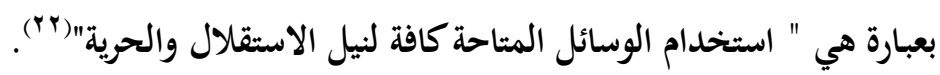

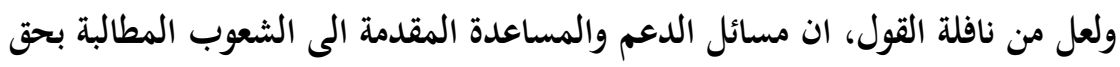

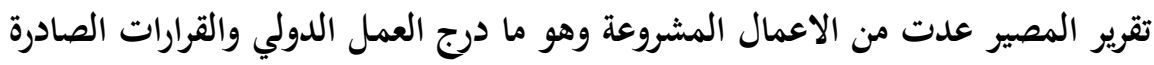

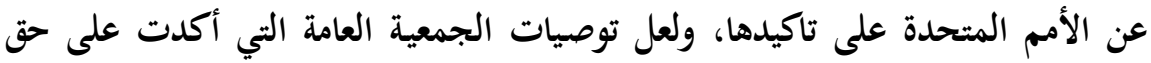

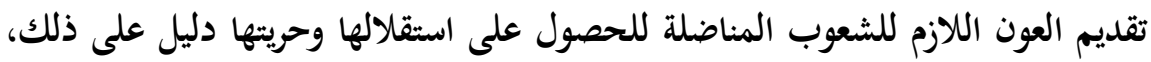

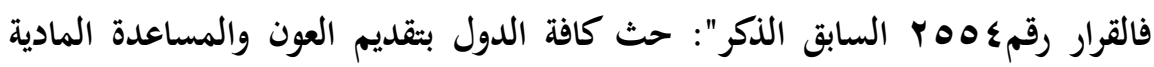

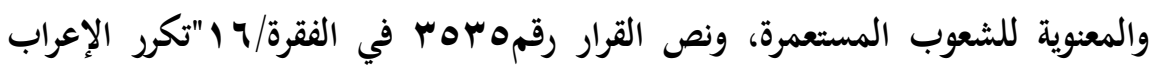


على تقديرها للمساعدة المادية وغيرها من المساعدات التي مازالت الشعوب الواقعة

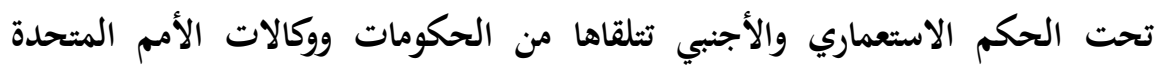

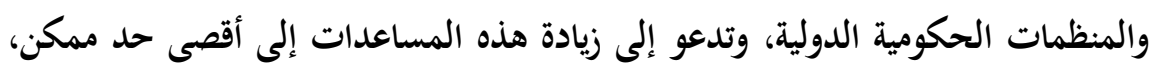
ونصت الفقرة/V منه على"أن تبذل أقصى جهودها لضمان التنفيذ التام لإعلان منح

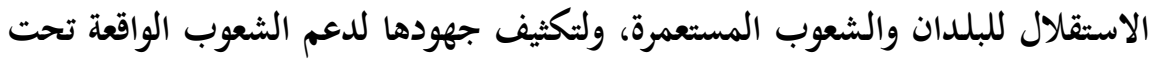
السيطرة الاستعمارية والأجنبية والعنصرية في كفاحها العادل من أجل تقرير المصير والاستقلال"(T) .يتضح مما سبق أن الشعوب المستعمرة المحتلة والخاضعة لنظام التمييز العنصري لها حق استخدام القوة ضد الدولة التي تمنعها من ممارسة حقها في تقرير

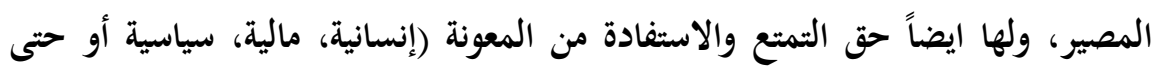

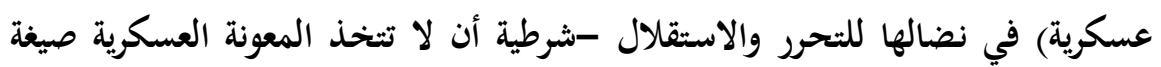

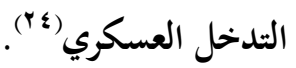
وهنا يثار التساؤل الاتي: هل ان اعمال حق تقرير المصير تتحدد بوسائل سلمية وغير سلمية فقط؟ الاجابة تدفعنا الى الاشارة الى انه ثمة وسائل اخرى يمكن تسميتها

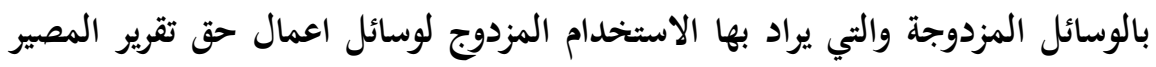

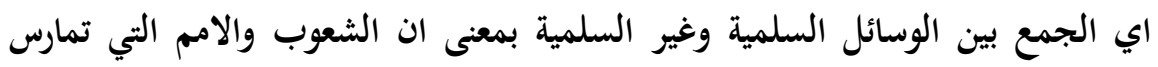

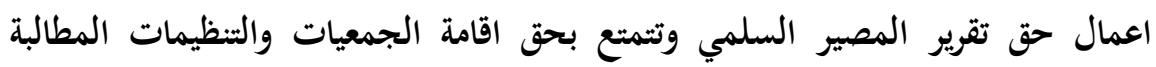

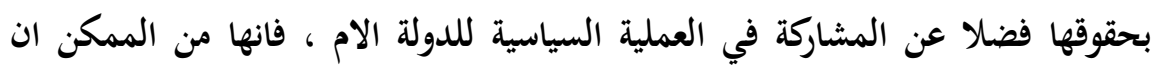

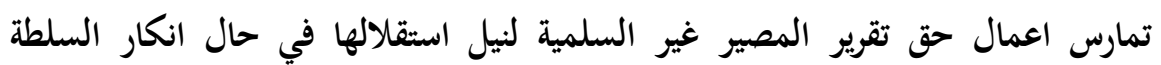

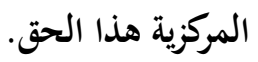
عموما، ان مطالب الجماعات القومية بإعمال حقها في تقرير المصير يتحدد بالدعم الخارجي، وهنا يكون للقوى الكبرى دور كبير في حسم العديد من مسائل حق تقرير

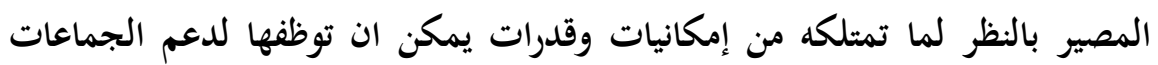

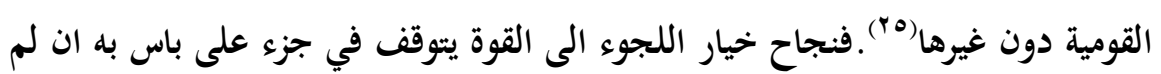
يكن الاكثر على دوافع الدول الكبرى وفي مقدمتها الولايات المتحدة الأمريكية في 
دعم مطالب بعض حركات تقرير المصير، وتجاهلها لمطالب حركات أخرى تعاني ذات الانتهاكات والاضطهاد من قبل الدول التي تخضع لها، وهو ما يستند بالدرجة الأساس

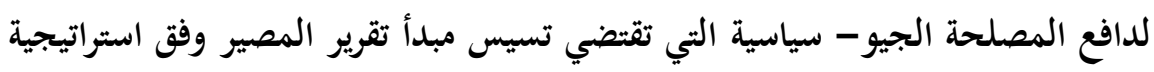

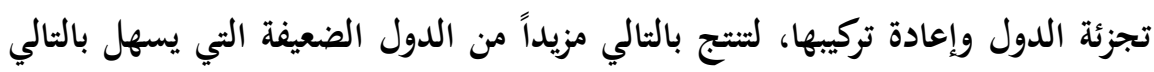

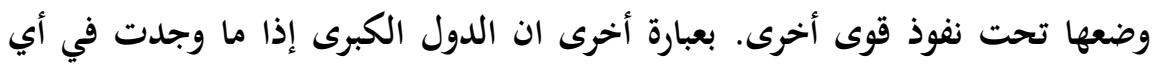

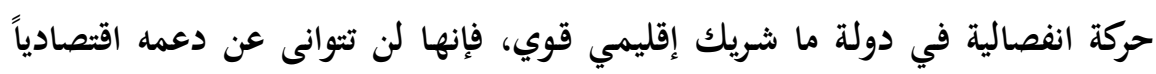

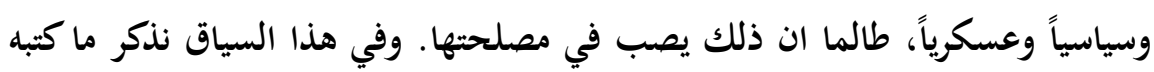
الباحث القانوني الافريقي مع انتهاء الحرب الباردة، بالقول ان

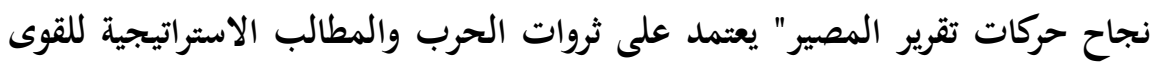

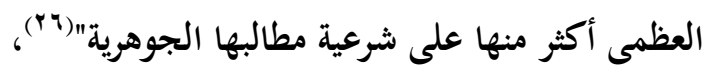
عليه فان أي محاولة للانفصال من قبل الجماعات القومية والأثنية في أي دولة سيتم التعامل معها سواء من ناحية الدعم او عدمه وفق لمنظور المصلحة السياسية بالدرجة

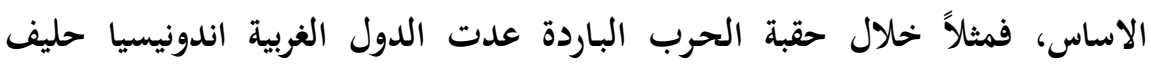
سياسي ضد الاتحاد السوفيتي فقدمت لها الدعم العسكري والمالي في حين تم تجاهل الهارل مطالب تيمور الشرقية في الاستقلال-آنذاك-، كذلك الحال بالنسبة لإقليم كوسوفو الذي عد شريك للغرب في مواجهة خطر توسع صربيا وتم دعم وتأييد استقلاله دون

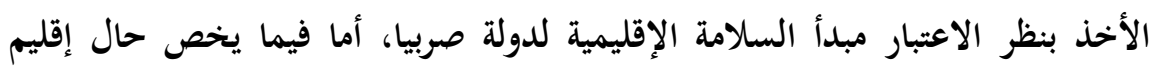

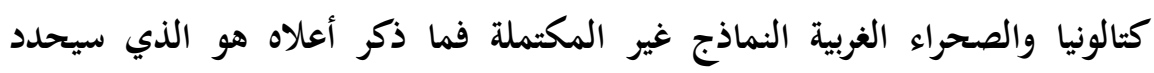
مصيرهما بالاستمرار أو الاستقلال.

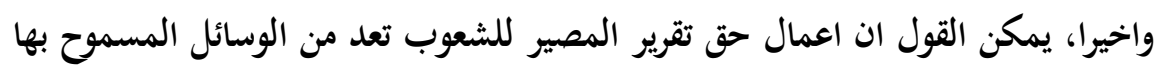
في اطار ممارسة هذا حق والتي تنطلب البعد عن اية ممارسات لا عقلانية ولا شرعية،

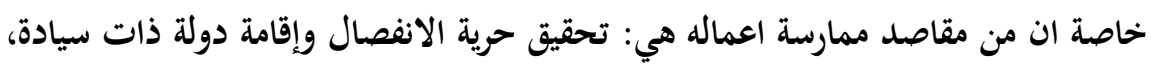

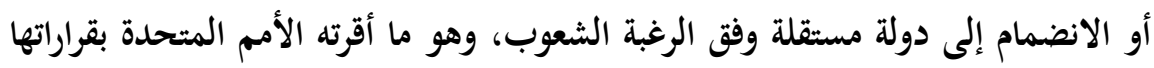
وإعلاناتها ومواثيقها، بيد ان تجارب المجتمع الدولي في ممارسة اعمال حق تقرير 
المصير تشير الى تطبيقات مختلفة يغلب على أكثرها مسألة استخدام الوسائل السلمية كإلاستفتاء، الذي يحدث في عالم اليوم ضمن إطار دولة قائمة ذات سيادة ونتيجة لئل لصراعات داخلية فيها، بيد ان ذلك لم يحول دون استخدام القوة باعتبارها وسيلة اخرى للممارسة وتحقيق مقاصده بالاستقلال او الانفصال او بالاستخدام المزدوج لوسائل اعماله.

المبحث الثاني :تطبيقات ممارسة اعمال حق تقرير المصير تعد وحدة الدول من أسمى المبادئ التي تعتز بها الأمم والشعوب قاطبة وتقدم في

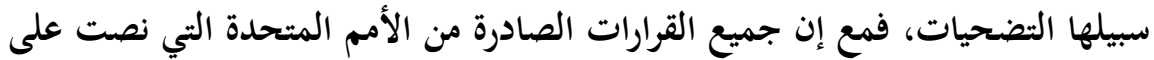
حق تقرير المصير نجدها أكدت أيضا على مبدأ السلامة الإقليمية والوحدة السياسية للدول المستقلة وذات السيادة، ومع إن عقد التسعينات من القرن الماضي شهدت سلسلة استفتاءات لبعض القوميات، التي مارست اعمال حق تقرير المصير غير ان

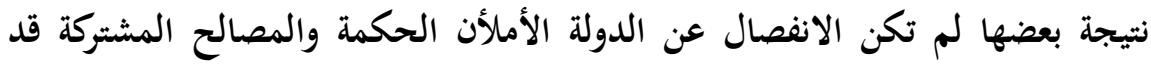
فرضت خيار الاستمرار فى الوحدة، وحالات اجري فيها الاستفتاء وكانت نتيجتها الاستقلال، وأخرى تأخر فيها اعمال حق التقرير إلى يومنا هذا. وبالنظر لكثرة النماذج سنتناول امثلة معينة وكالآتي:

$$
\text { المطلب الأول: النماذج السلمية: }
$$

نعمد خلالها الى تناول نموذجين لتقرير المصير باستخدام الوسائل السلمية احدهما

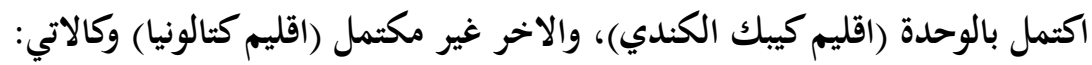
اولا : اقليم كيبك الكندي (الوحدة): يمثل إقليم كيبك تجربة للفدرالية المركزية(YV)، فرغم محيطه الانغلوفوني الناطق النق بالانكليزية نجده يضم أغلبية كندية ذات ثقافة فرنسية، ييعود وجودها لحركة الاستيطان الفرنسية شمال القارة الأمريكية منذ القرن VV، لم فمع تنازل فرنسا عنها لصالح بريطانيا

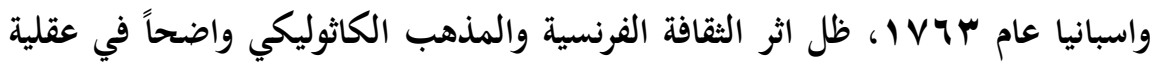


الكنديين الفرنسيين بفعل حركات التبشير الكاثوليكية، التي خضعوا لها ثقافياً وسياسياً(r^)

ورغم مظاهر الاختلاف الثقافي والسياسي لكيبك، التي حاول النظام الكندي استيعابه

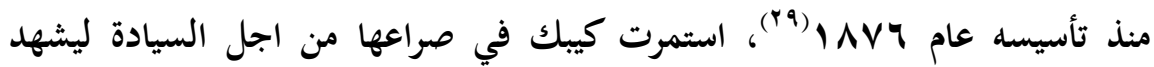
النظام الفيدرالي الكندي سلسلة مطالب ودعوات بالانفصال تصاعدت بعد ممارسات حكومة دوبليسيس الذي تلاعب بنتائج الانتخابات وسيطر على موارد الاقليم وهو ما

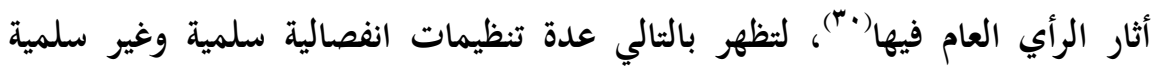

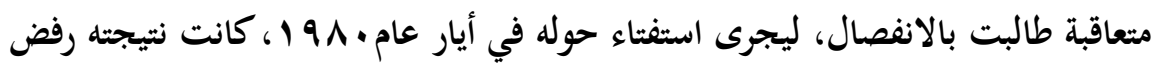

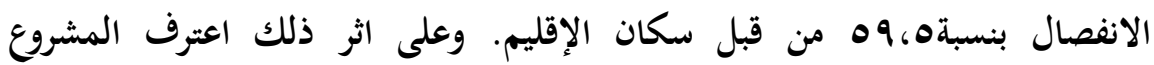
الفيدرالي لها بسيادة الانضمام واتسع استقلالها الذاتي واكتمل برابطة اقتصادية مع الإنى

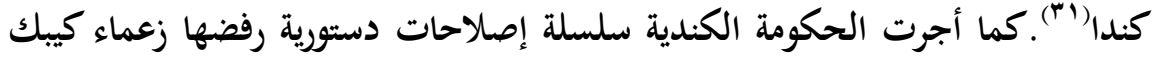
بدعوى ان ميثاق الحقوق والحريات لا يراعي الظروف الخاصة بكل إقليم، لتنزايد حدة الخحلافات بين الطرفين ورغم محاولات الحكومة الكندية التوصل الى اتفاقات تتضمن

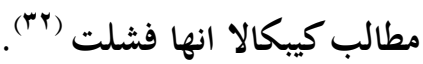

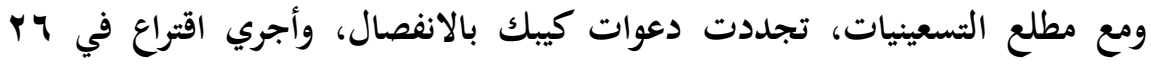

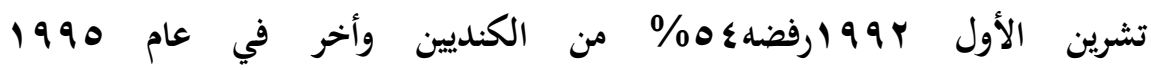

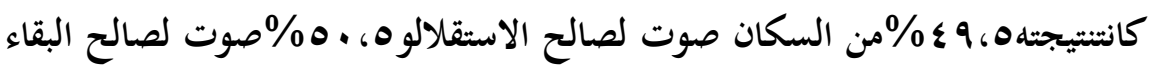
ضمن كندا الفيدرالية.

وفي ضوء ما أثارته النتيجة من جدل ولكي تقي الحكومة الكندية نفسها من أي محاولة

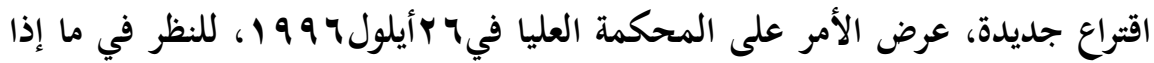

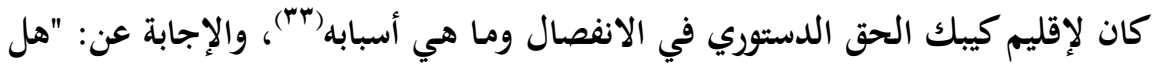
يوجد في القانون الدولي حق تقرير مصير يعطي كيبك حقا للانفصال أحادي الجانب"،

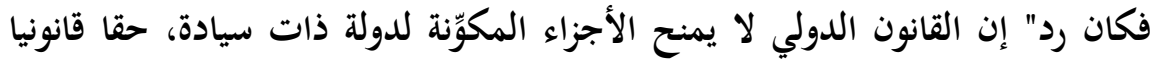

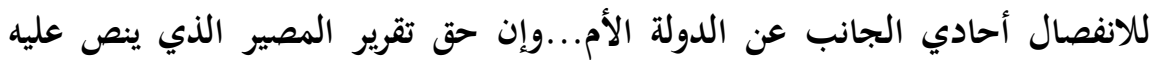


القانون الدولي لا يُنشيء سوى حق تقرير للمصير الخارجي في حالات المستعمرات

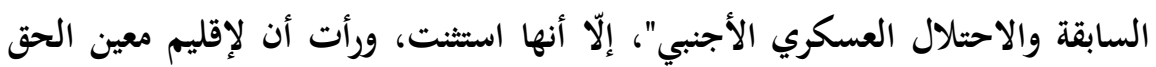

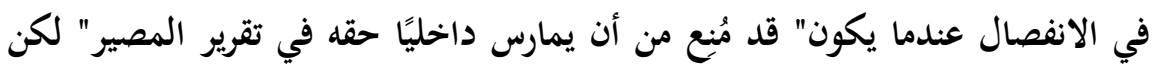

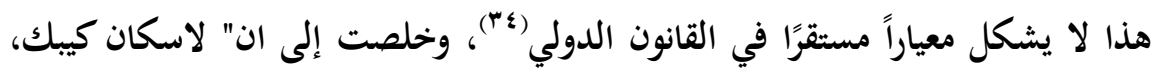

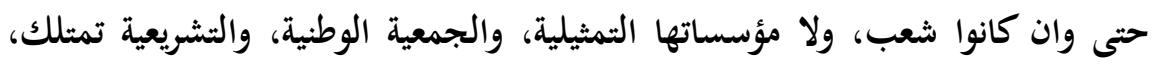

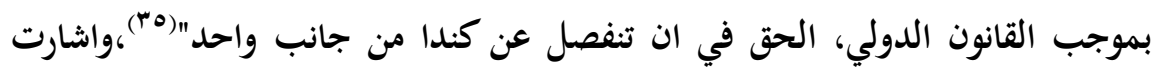

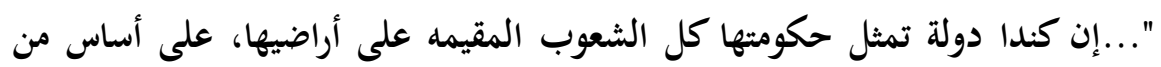
المساواة دون تمييز، وتحترم مبادئ تقرير المصير في داخلها، والحق في الحماية

بموجب القانون الدولي" (بَ). وأصدرت قرارها عام 1991، 19، أكدت فيه إن إي طلب لانفصال إلاقليم يتطلب

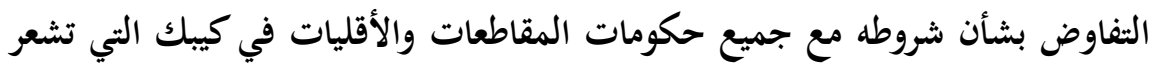

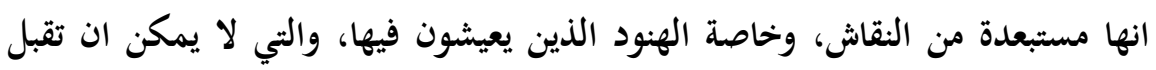

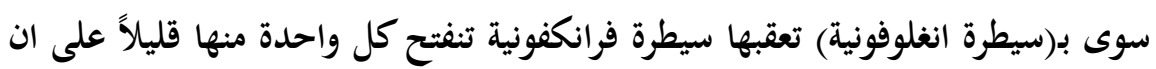

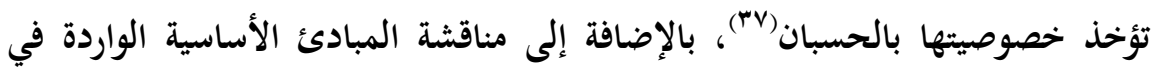

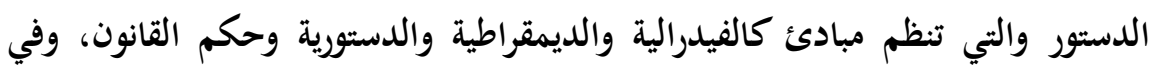
النهاية فأن الانفصال يتطلب التفاوض على تعديل القوانين الأساسية (الدستور) (^هائ.

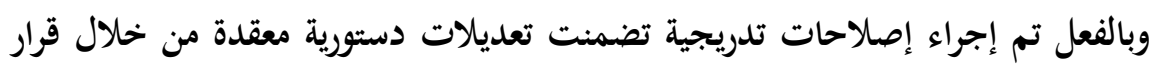
برلماني وتشريعات حققت من خلالها بعض مطالبها (ra).

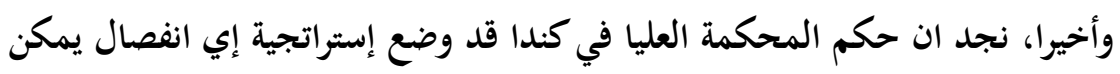

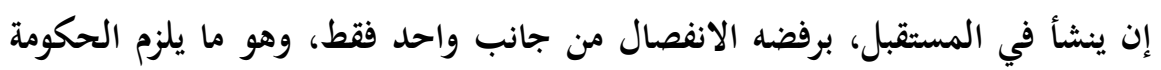
الاتحادية والولايات الأخرى بالتفاوض بحسن بنية الانية حول مسائل من قبيل الأغلبية المطلوبة للانفصال وحدود الإقليم المنفصل وضمان حقوق الأقليات، إضافة إلى مسائل بحانل أخرى يتطلب الاتفاق عليها قبل إجراء الاستفتاء والتي تتضمن حتما تعديل الدستور. 
كما اظهر استفتاء الاقليم والمواقف الدولية حياله عدم قدرة وإمكانية أي فدرالية على تحقيق التوازن بشكل دائم بين الحق والتنوع وتأكيد وحدة الدولة.

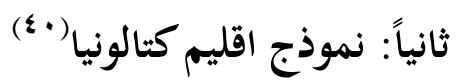

تعود مطالب الانفصال عن اسبانيا في جذورها الى حقب طويلة، كان أعنفها في

إقليم كتالونيا التي حصل على الحكم الذاتي عام اسو 1)، لكن مع تصاعد حجم

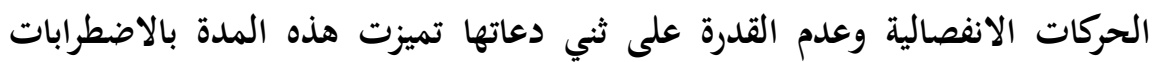

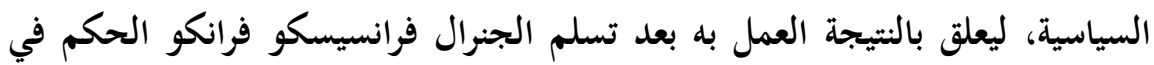
\با9 ا، الذي قمع جميع الأنشطة العامة المرتبطة بالقومية الكاتالانية، الأناركية،

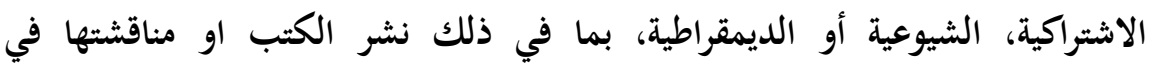
جلسات مفتوحة، ومنع استخدام اللغة الكاتالونية في المؤسسات التي تديرها الحكومة وفي المناسبات العامة، فضلا عن اساليب القمع الممنهج للقومية الكاتلونية، وفي هذا الصدد كتبت صحيفة نيويورك تايمز "حاولت الحكومة القضاء على اللغة والانشطة في جميع المؤسسات الكاتالونية، وتم إعدام آلاف الأشخاص في عمليات التطهير، عمليا

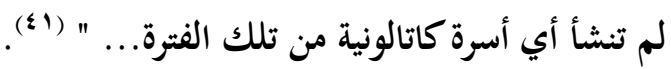

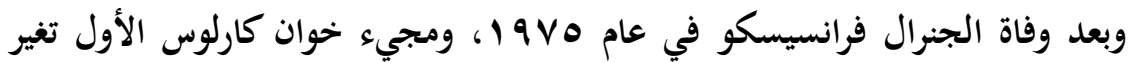

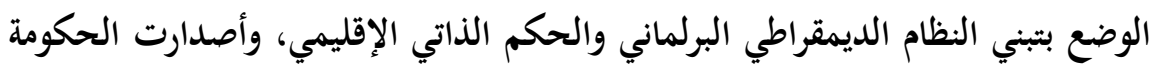

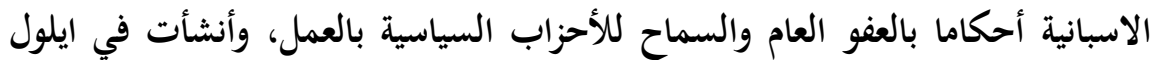
19VV

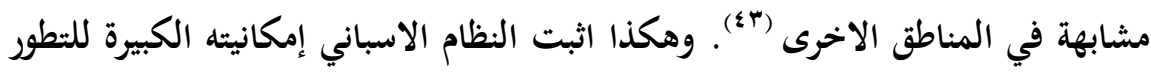
من خلال الآليات التي تسمح بالتغيير في التوزيع الدستوري للسلطة وفي تفسير

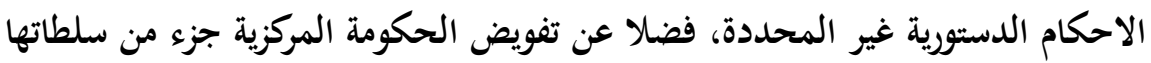

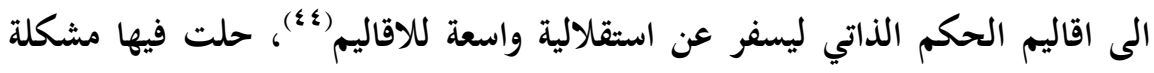
التنوع الثقافي والعرقي وأصبحت اسبانيا نموذج لمحاولة استيعاب التباينات عن طريق

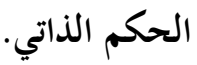




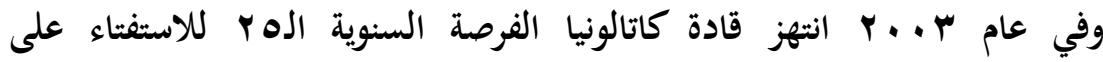

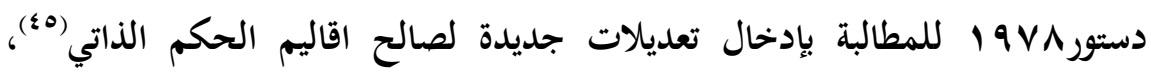

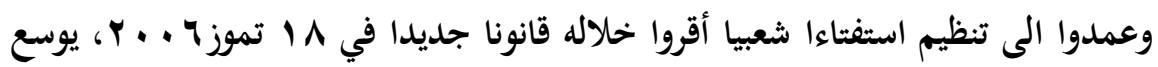

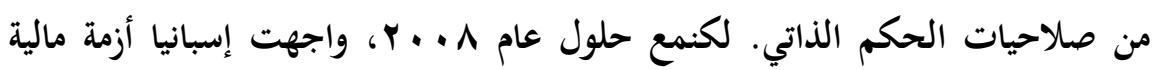
تسببت في إجراءات تقشف وفترات ركود قاسية استمرت سنوات، أبطلت على اثرها

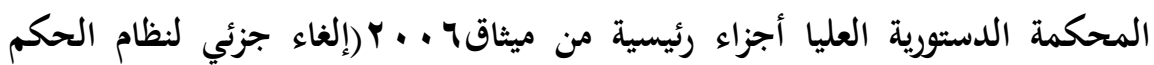
الذاتي)، وهو ما ولد إحساسا لدى سكان وحكومة كتالونيا مفاده أن لإقليمهم إمكانيات تمكنه من تحقيق التنمية والتقدم اذا ما انفصل (؟؛). لتتصاعد النزعة الانفصالية للإقليم ممثلا بالجمعية الوطنية، التي عملت جاهدة الى حشد الجماهير في مظاهرات تخرج

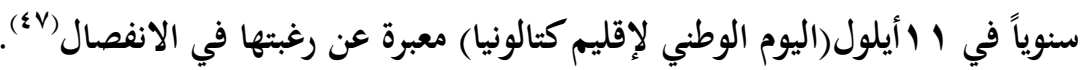
ورغم رفض الحكومة الإسبانية منح استقلال مالي أكبر للإقليم، وأصدار محكمتها لإنيا

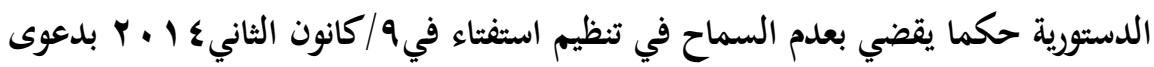

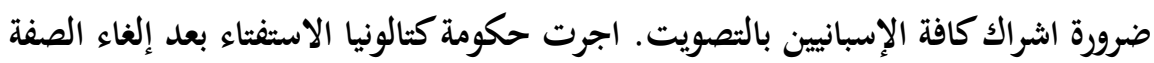
الرسمية له، وهكذا صوت أكثر من •^^\% لصروالح الانفصال، غير ان الحكومة الإسبانية

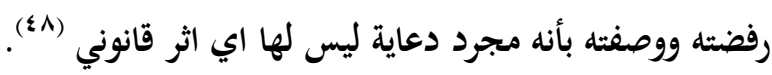

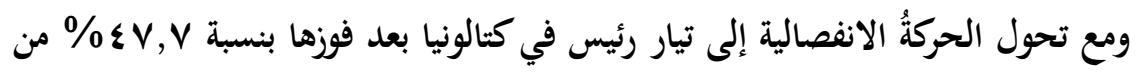

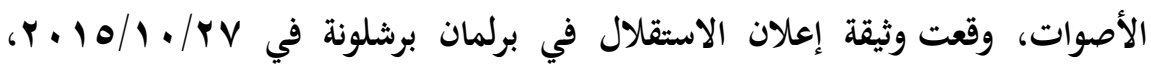

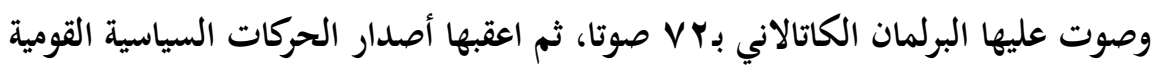
الكاتالونية سلسلة قرارات، منها صياغة مسودات الدستور والضمان الاجتماعي ومصلحة

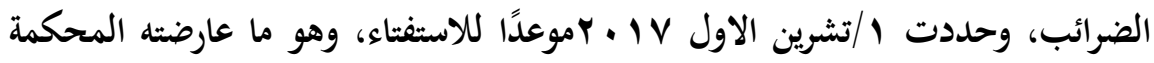
الإسبانية العليا والغت نتائجه، وعرقلت أي محاولة استقلال مؤكدة أن إجراءه غير

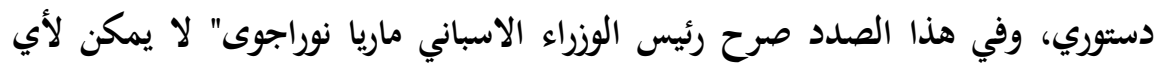
حكومة في أي بلد ديمقراطي أن تقبل بانتهاك القانون وتجاهله وتغييره "(9 \&.). 
كما اعتمدت الحكومة الاسبانية سلسلة إجراءات أحبطت بدورها الاستفناء في

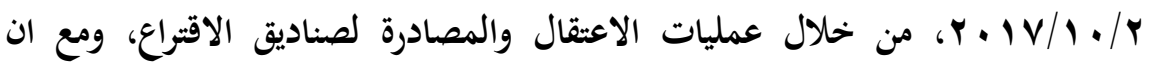

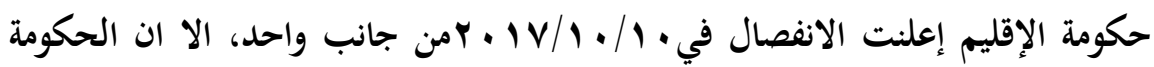
ردت عليه بسلسلة اجراءات منها تعليق الحكم الذاتي للاقليم، وهنا يثار التساؤل الاتي:

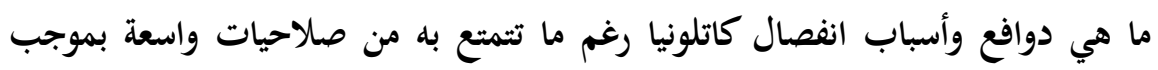
الحكم الذاتي؟ الإجابة تقتضي الإشارة الى ما أعلنه رئيس كاتالونيا السابق أرتور ماس بأن أنس

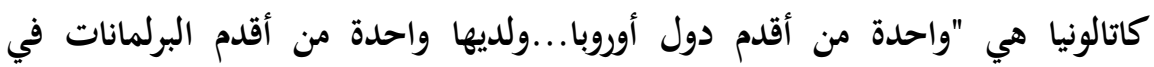

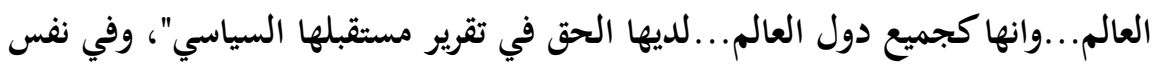

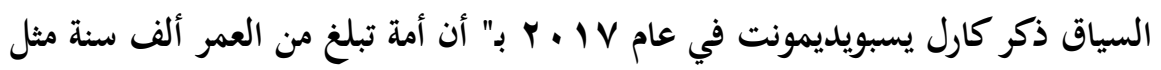

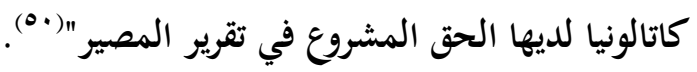
وتمثل هذه الدعوات مطالب كلاسيكية بتقرير المصير، وليس مطالب عرقية-وطنية،

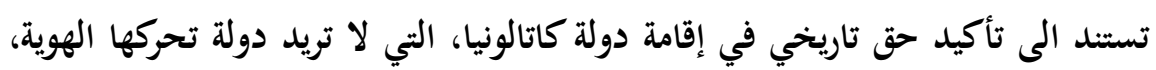

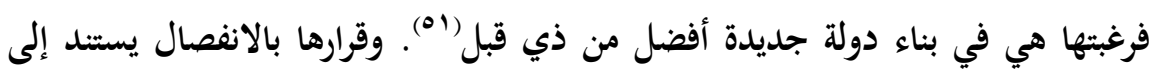

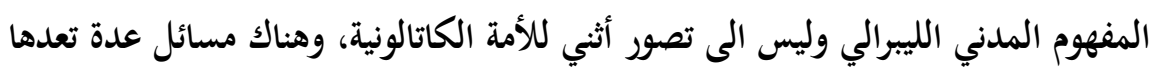

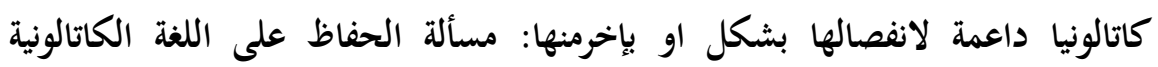

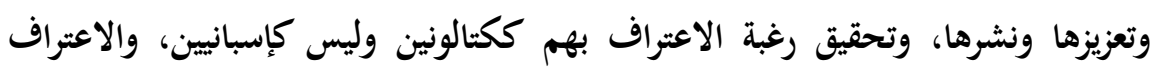
بثقافتهم كثقافة مستقلة والتخلص من سيطرة الثقافة الإسبانية، وإدارة مواردها الطبيعية والبشرية، مع تحديد مركزها السياسي والسعي بحرية إلى تعزيزها اقتصادياً واجتماعياً وثقافياً (ه).

وأخيراً، فان الصيغة التي اعتمدتها الحكومة الاسبانية من خلال التسوية القائمة على نقل السلطة من المركز إلى الجهات، وان كانت دليل على نجاح صيغة الحكم الذاتي لكل

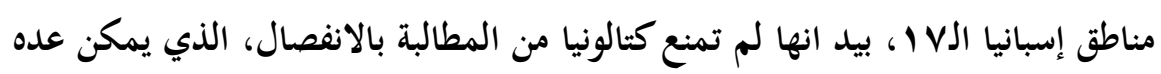

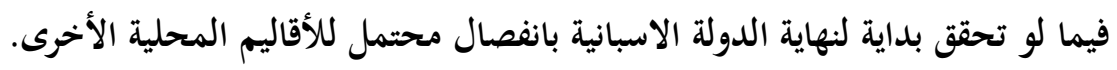


المطلب الثاني : النماذج غير السلمية والمزدوجة: نتطرق خلالها نموذجين لوسائل اعمال حق تقرير المصير(الوسائل غير السلمية والوسائل المزدوجة) بالنظر لصعوبة الفصل بين وسائله هذه في ان واحد، فيكل فيل وسيلة

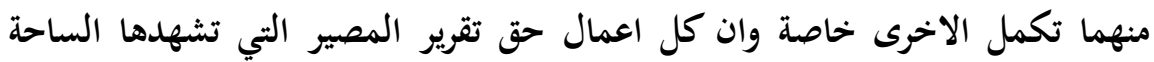

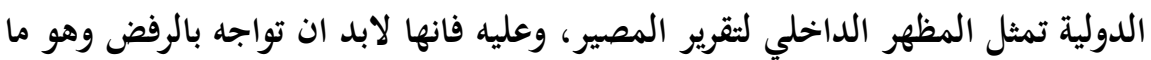
يتطلب الركون الى الوسائل غير السلمية لتحقيق مطالبها في بادئ الامر ومن ثم استخدام الوسائل السلمية، وكالاتي: الوالي:

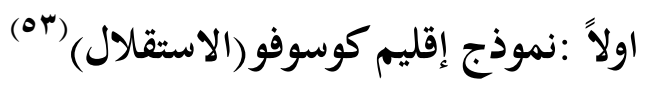

لقد كان إقليم كوسوفو جزءاً من الدولة العثمانية طيلة خمسة قرون، منذ ان فتحها

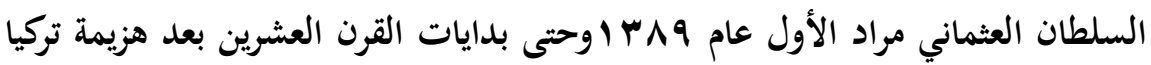
في الحرب العالمية الأولى، لتصبح بعد سلسلة مؤتمرات دولية تحت السيطرة الصربية

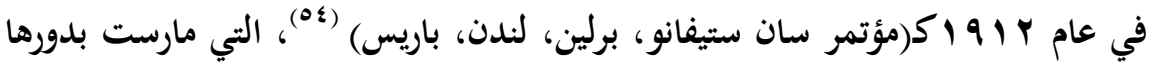

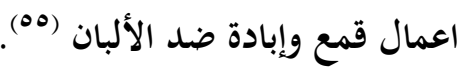
وبعد الحرب العالمية الثانية، ضم اقليم كوسوفو الى اتحاد الجمهوريات اليوغسلافيا

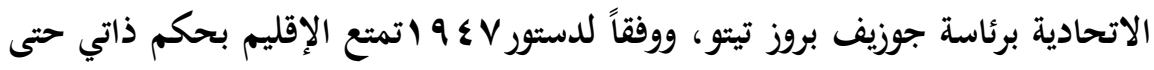

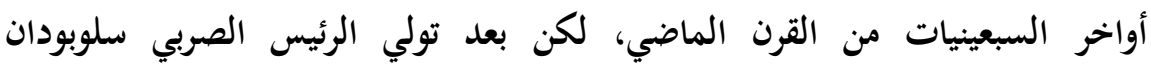
ميلوسوفيتش الحكم في 9AV 19 ب، بأت المشكلة الكوسوفية بعد قيامه بإلغاء الحكم الذاتي الذي كان يتمتع به الإقليم، وعزل العديد من النواب المنتمين للقومية الألبانية في البرلمان الكوسوفي، وحكم الإقليم بأساليب قمعية عنيفة، أدت إلى تدمير استقلاله

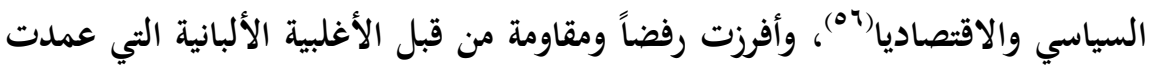
الى تشكيل تنظيما قوميا بقيادة حزب الاتحاد الديمقراطي الألباني برئاسة إبراهيم

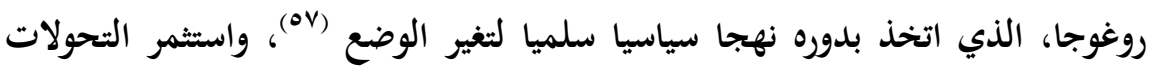
التي شهدها مطلع التسعينيات عقب تفكك الاتحاد السوفيتي ويوغسلافيا، ودخول منطقة البلقان مرحلة معقدة عرفت بالبلقنة . 
وفي ضوء ما تقدم، طالب سكان الإقليم بالاستقلال والاعتراف بخصوصيتهم القومية

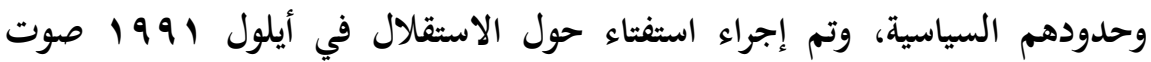

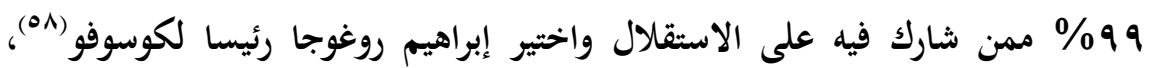
لتشهد المنطقة صراع وصل الى حد ارتكاب مذابح وانتهاكات عديدة، اصدر على أثرها

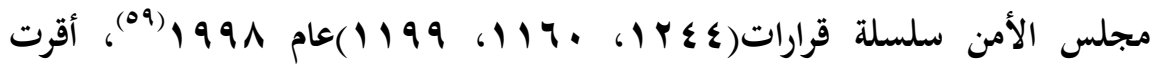
بخطورة الأوضاع في كوسوفو وتأثيرها الخطير على منطقة البلقان وتهديد السلام والأمن

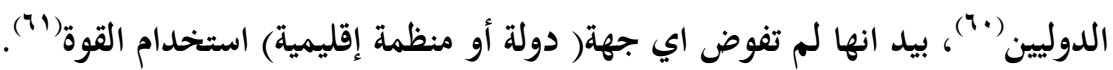
ومع استمرار المجازر الوحشية وجرائم الإبادة الجماعية شن حلف شمال الاطلسي في آني

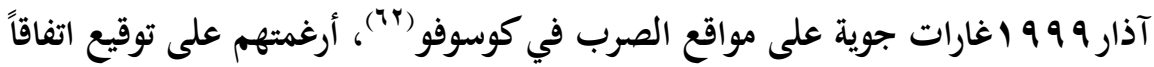
يقضي بالانسحاب من كوسوفو ووقف العنف ووضع مراقبين على طول خطوط القتال

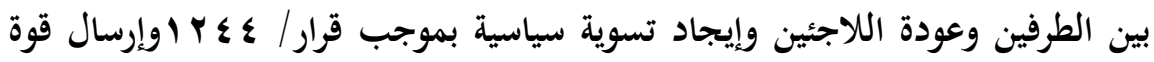
من الامم المتحدة سميت بـ(UNMIK) يترأسها ممثل عن الأمم المتحدة يكون الحاكم

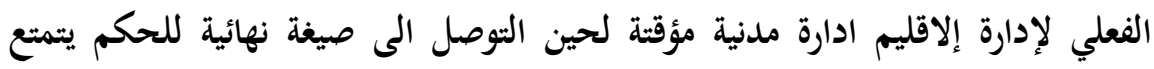
خلالها الإقليم باستقلال ذاتي كبير ودرجة معقولة من الإدارة الذاتية داخل جمهورية يوغوسلافيا الاتحادية ("آ). وفي ظل الإدارة الدولية أجريت اول انتخابات ديمقراطية لانتخاب برلمان جديد في

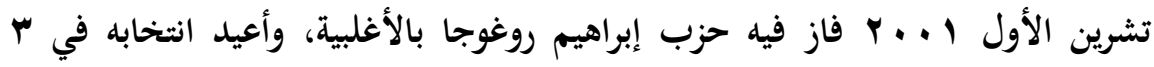
كانون الأول ع . . . . غير ان تجدد إعمال الشغب والقتل والطرد للسكان غير الألبان من الإقليم من جهة، وإصرار سلطات بلغراد على المطالبة بتطبيق صارم ودقيق لقرار

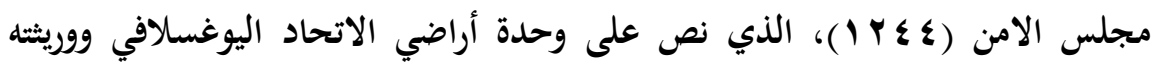

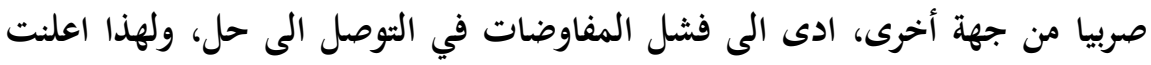

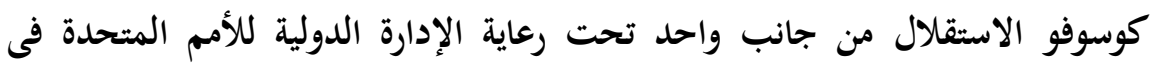

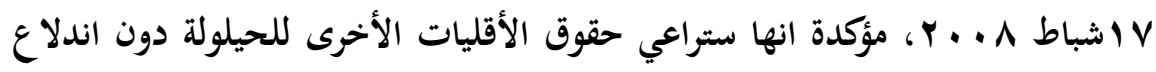


أي عنف خاصة من جانب الصرب الذين بدأُ بالعنف، كما وعدت الأقليات بنوع من الإدارة اللامركزية فى إدارة مناطقها (\$ج"). وهكذا، فان فشل مجلس الامن في التوصل الى قرار يمنح إقليم كوسوفو حق تقرير

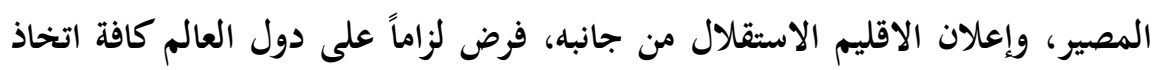

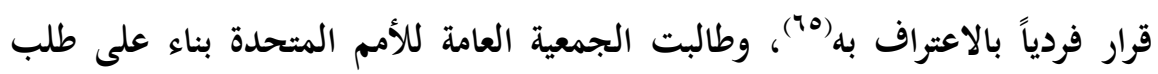

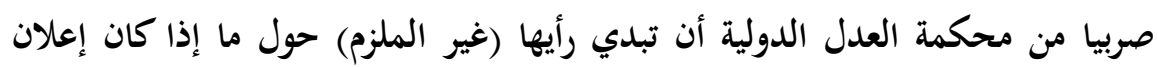

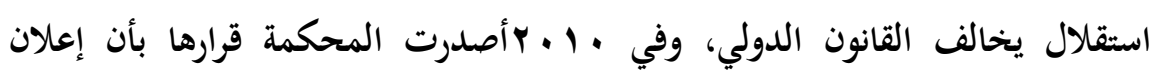

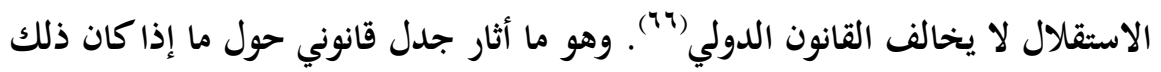
يعد سابقة في القانون الدولي تمنح الأقليات حق الانفصال من جانب واحد.

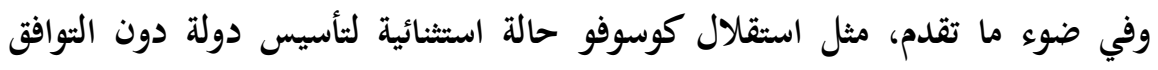
الكامل مع القانون الدولي، والذي يمكن تفسيره في ضوء الدعم الغربي الواسع، فضلا

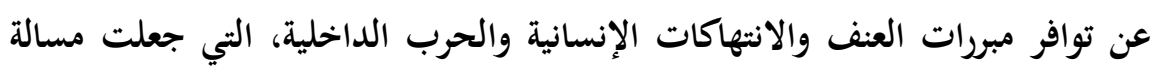

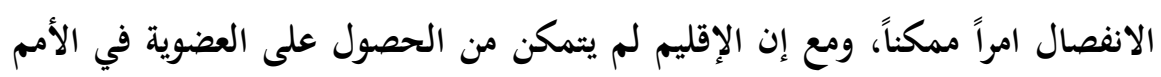

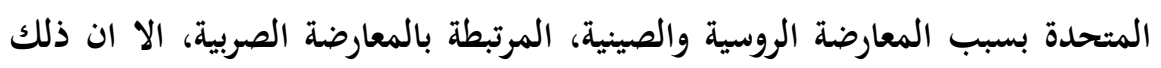

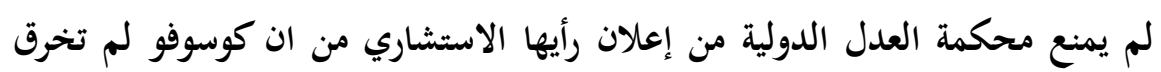

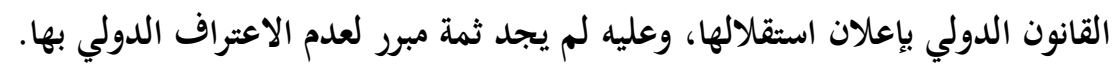

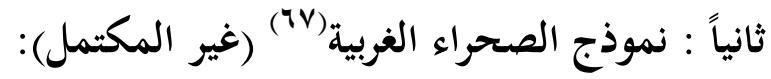

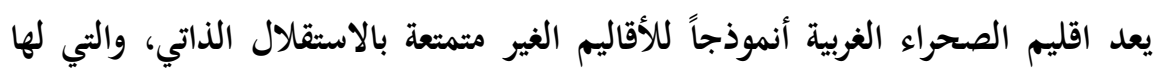

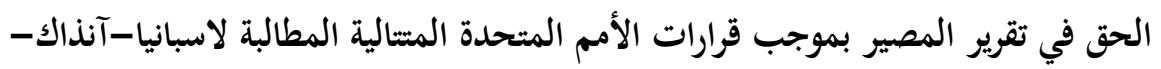

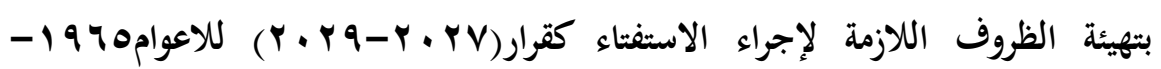

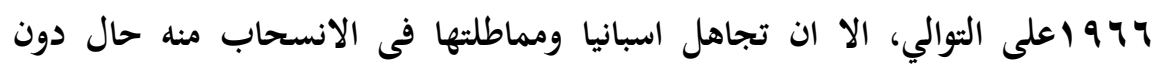
تنظيمه ("). ومع مطلع السبعينيات برزت قضية الصحراء بشدة على اثر اشتداد عمليات المقاومة الوطنية المسلحة ضد الأسبان فيها، وظهور (البوليساريو) كقوة عسكريةقادت الكيه الكفاح 
المسلح، وعدت نفسها صاحبة الحق في إدارة شؤون الإقليم(99)في حين طالب

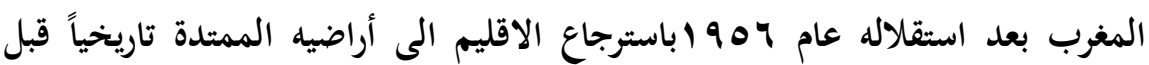

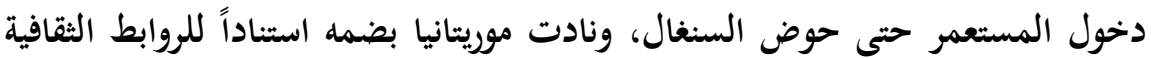
واللغوية والعلاقات الاقتصادية معه، اما الجزائر وليبيا فرأت ان حل المشكلة يكون

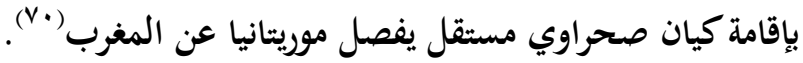
وفي عام ع ا9V قررت اسبانيا وبناءاً على اقتراح الجمعية العامة للأمم المتحدة وقرارها في حق شعب الصحراء تقرير مصيره، أجراء استفتاء باشراف جيمس بيكر وزير الخارجية الحتية الامريكي الأسبق مع إعطاء صلاحيات واسعة لمجلس العموم الصحراوي (الجماعة) بإشراف الأمم المتحدة،وهو ما أثار حفيظة المغرب التي عرضت المسالة على محكمة العدل الدولية فى ع 19V، بغية تحديد المركز القانوني للإقليم وإيقاف أي عملية استفتاء فيه، وقدمت عدة ادلة على عائديته لها، وبعد التدقيق والتفحص توصلت المحكمة في رأيها الاستشاري فى تشرين الاوله 9 V الى عدم وجود أي روابط قانونية أو إقليمية بين الإقليم من جهة والمغرب او وموريتانيا من جهة أخرى، وأيدت

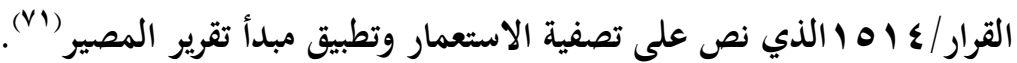
ولغرض الاستحواذ على الاقليم وتأكيد عائديتها للمغرب، أعلن الملك الحسن الثاني

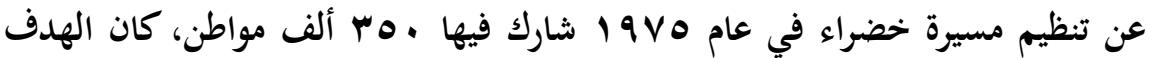
منها فرض الامر الواقع ودفع اسبانيا والامم المتحدة إلى فتح مفاوضات مباشرة من أجل

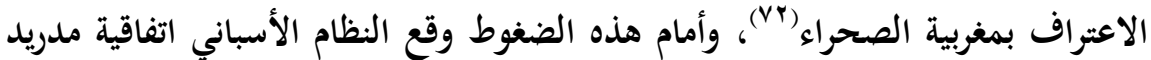
الثلاثية عام هV (1)، تم بموجبها إنهاء الوجود الإسباني في الصحراء ودخول القوات

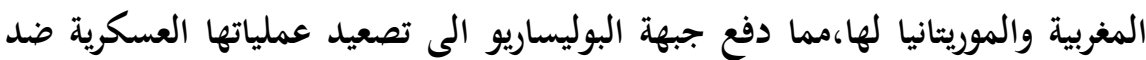
الأسبان رداً على الاتفاقية، التي عدتها بمثابة اعتراف ضمني من الاخيرة بإقصاء الجبهة من الصراع، ودفعها من جهة اخرى الى الاعلان عن قيام الجمهورية العربية الصحراوية

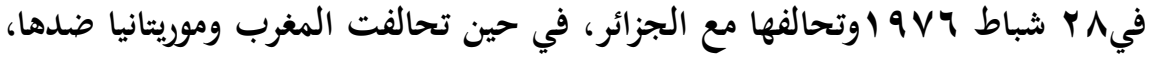
لتندلع بالثالي مواجهة عسكرية استمرت ثلاث سنوات انسحبت على اثرها موريتانيا 


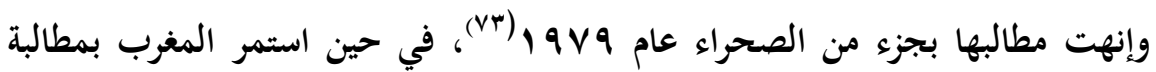

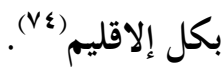
وفي العام نفسه، اعترفت الامم المتحدة بالجبهة كممثل شرعي لسكان الصحراء، وقدمت

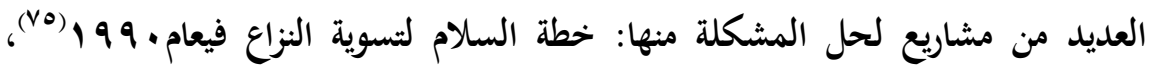

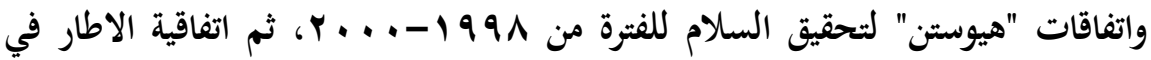

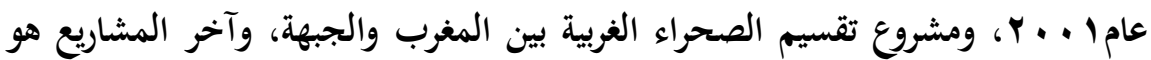

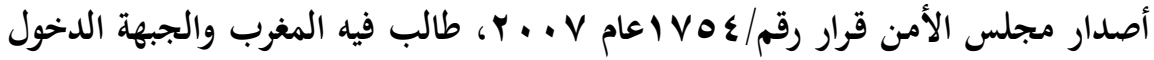

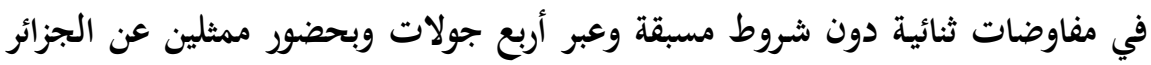

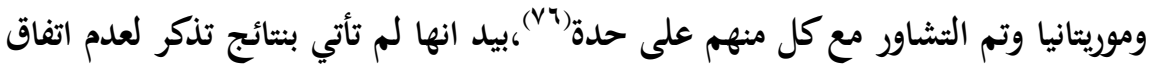

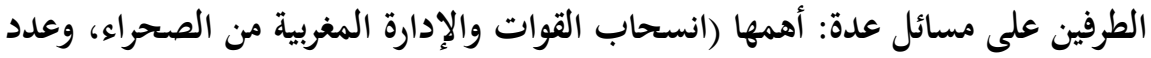

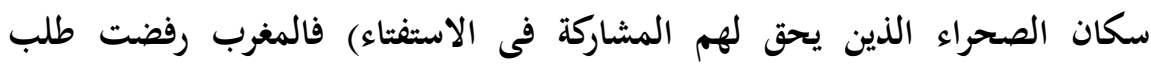
البوليساريو بإضافة الصحراويين فى الخارج، والجبهة رفضت أية تسوية لا تتضمن حق لق

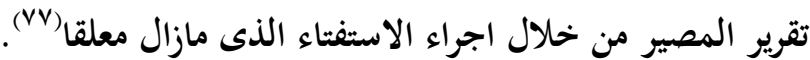
واخيراً، فان الاستفتاء على تقرير مصير الصحراء قد تأخر الى يومنا هذا رغم المقترحين

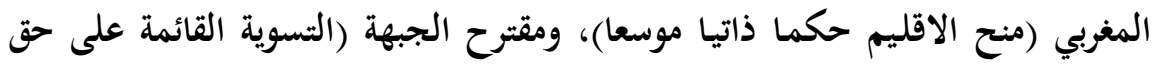
تقرير المصير) اللذان يعدان من الحلول والمبادرات العديدة والتقليدية، التي طرحت الته

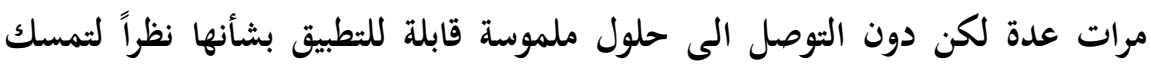
أطرافها بها. صفوة القول، ان التطبيقات أعلاه بمجملها لممارسة أعمال حق تقرير المصير تمثل البعد الداخلي لحق تقرير المصير وتعكس بلدورها ممارسة الشعب لحق هو من صلب

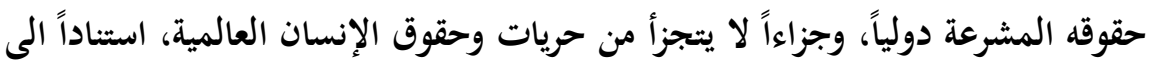

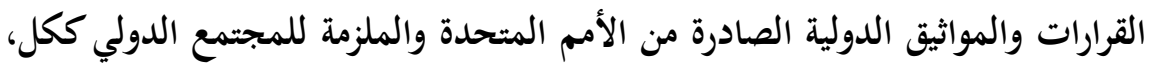
بالتالي فان مسالة تحديدها او منعها أمر مرفوض وغير ممكن ان صح انح التعبير. 
الخاتمة (استنتاجات) تتحدد مشروعية اعمال حق تقرير المصير وفقا للتجارب الدولية الى وسائل سلمية، ووسائل غير سلمية بالاضافة الى وسائل مزدوجة، لكن رغم كفالتهما من قبل التهير القانون

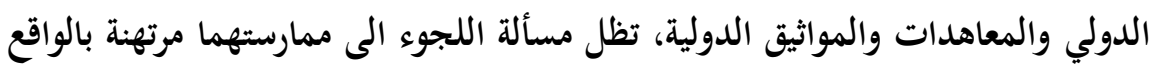
السياسي لكل منطقة، خاصة بعد ان طويت صفحات الاستعمار والتمييز العنصري، وبدأ الحديث عن حق تقرير المصير القومي منذ مطلع التسعينيات، بيد ان ذلك لا يحول

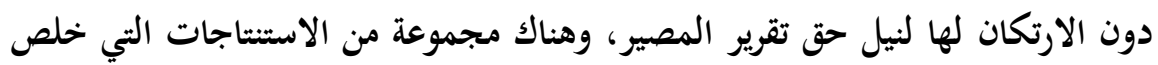

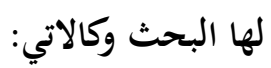

- - متراوح اعمال الجماعات القومية والعرقية في تقرير مصيرها ما بين وسائل ذات طابع سلمي ووسائل ذات طابع غير سلمي واخرى مزدوجة تجمع بين خيار العنف واستخدام السلاح في حالة الرفض من قبل السلطة والنظام السائد

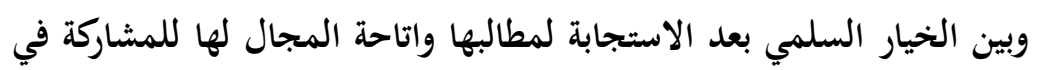

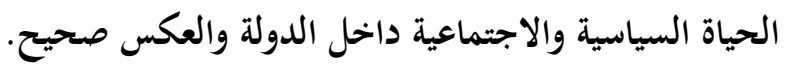
- - اضحت قوى التفكك والانفصال في عالمنا المعاصر اكثر قوة من قوى التماسك والاندماج، فجميع الدول في العالم منذ نيلها الاستقلال والتحرر

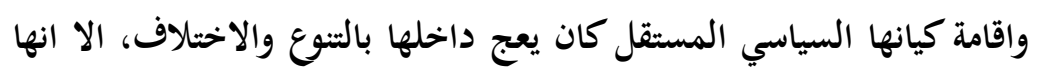

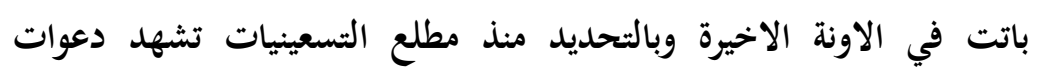
ومطالب للانفصال وفقاً لحق تقرير المصير. - - العلاقات الدولية كما هو معروف تقوم على المصالح ، وهو ما جعل اعمال

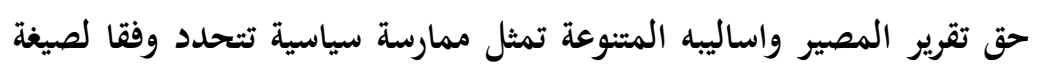

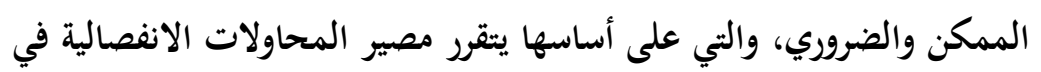

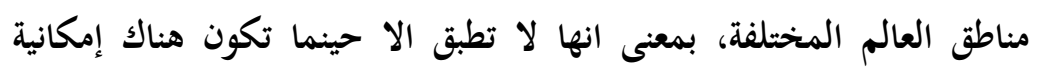

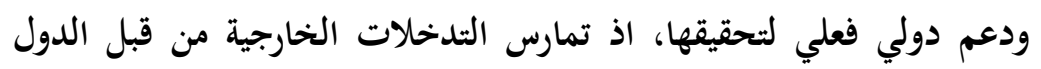


الكبرى او دول الجوار الاقليمي عامل دعم واسناد لمطالب الجماعات القومية والعرقية بالانفصال او الاستقلال لدوافع واسباب عدة تتعلق بالمصالح

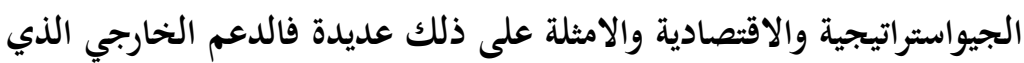
حظي به اقليم كوسوفو كان السبب الاهم في استقلاله .

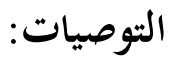

ثمة اليات ووسائل اخرى يمكن عبرها تحقيق مطالب الشعوب والجماعات الراغبة بالانفصال منها:

- دراسة معمقة وموضوعية لجذور واسباب دعوات الانفصال ومراحل تطورها وتداعياته المحتملة ومن ثم العمل على وضع معالجة منهجية وبناءة تتجاوب

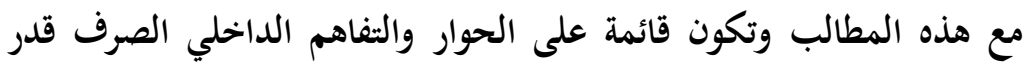

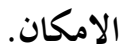

- - جذب الفئات المطالب بالانفصال الى المشاركة في الحياة السياسية والاجتماعية وعمليات التنمية الوطنية عبر صيغ ممنهجة ولاتقليدية تراعي الاختلافات الاثنية والعرقية وتحافظ في الوقت نفسه على ولى وحدة الكيه الكيان السياسي القائم واستمراريته.

- - مامة الندوات وورش العمل الثقافية والثوعوية لبيان اهمية الاندماج والثماسك

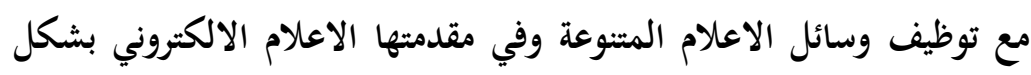

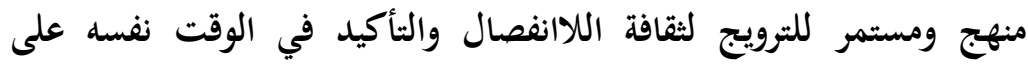

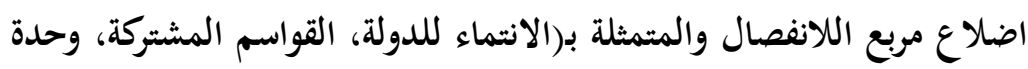

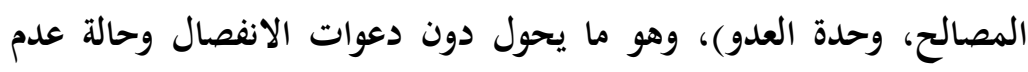
الاستقرار التي ترافتها.

\section{Abstract}

The means of self-determination have their peaceful and non-peaceful dimensions and are united(peaceful and non-peaceful) by international consensus adopted by international conventions and 
instruments. This has given it various dimensions at the applied level, especially in the light of the contemporary international developments witnessed by the world represented by a number of complete and incomplete implementation models that have nothing to do with the theory of truth Self-determination associated with the liberation of peoples from colonial domination or the liberation of oppressed nationalities.

- Keywords: (self-determination, means of self-determination, models of self-determination).

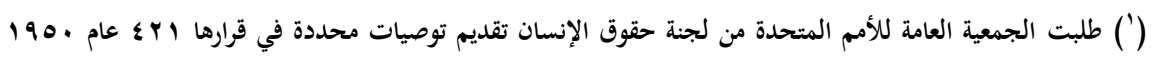

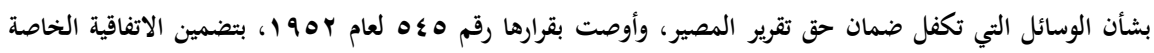

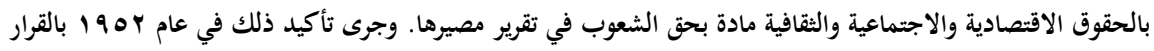

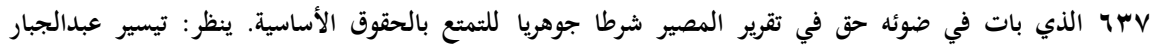

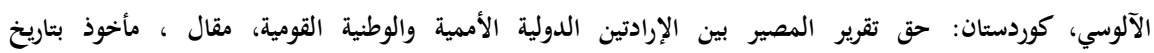
www.gulanmedia.com/arabic/articles.php?eid=8\&id=37

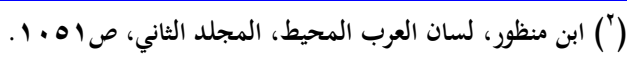

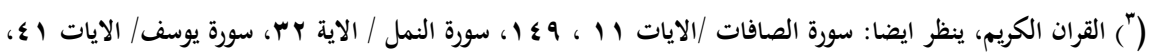

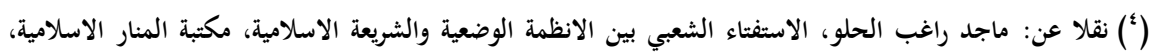

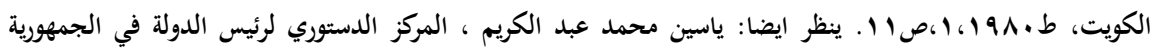

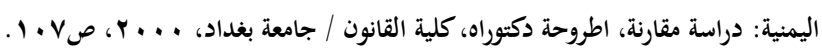

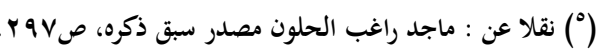

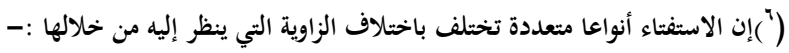

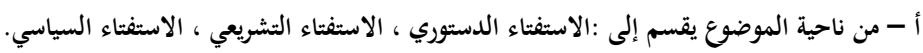

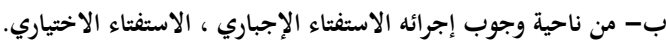

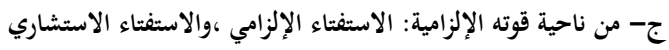

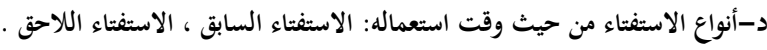

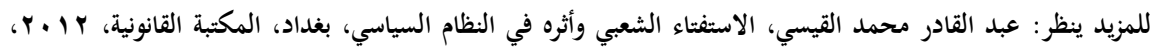
صar ( احسان المفرجي واخرون ، النظرية العامة في القانون الدستوري والنظام الدستوري في العراق، دار الحكمة ، بغداد، 


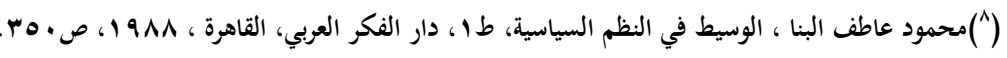

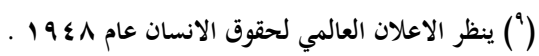

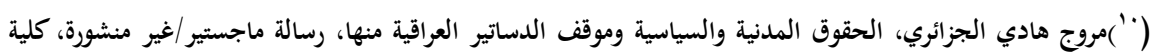

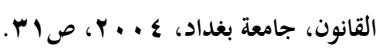

(") كرم سعيد، التحركات الانفصالية في العالم: نموذج كتالونيا، مجلة السياسة الدولية، مركز الاهرام للدراسات السياسية

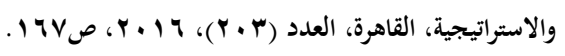

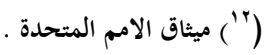

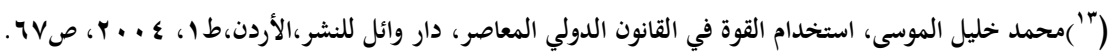

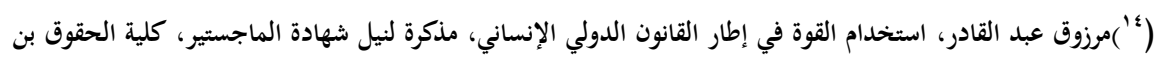

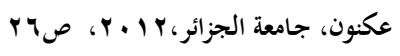

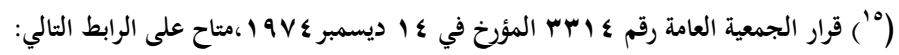
http://www.un.org/en/ga/search/view_doc.asp?symbol=A/RES/3314(XXIX)\&referer

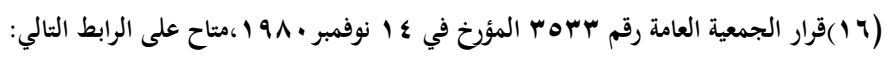

http://www.un.org/en/ga/search/view_doc.asp?symbol=A/RES/35/33\&referer

(IV) http://www.un.org/en/ga/search/view_doc.asp?symbol=A/RES/1514(XV

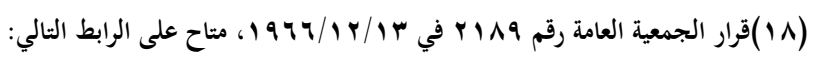

http://www.un.org/en/ga/search/view_doc.asp?symbol=A/RES/2189(XXI)\&referer

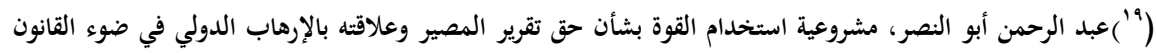

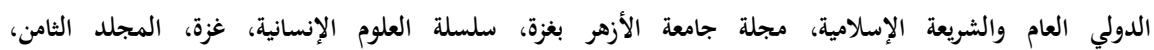

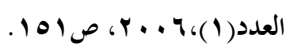

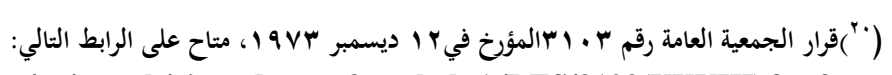

http://www.un.org/en/ga/search/view_doc.asp?symbol=A/RES/3103(XXVIII)\&refere

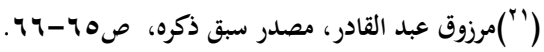

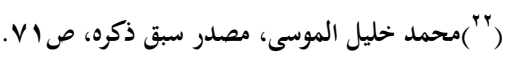

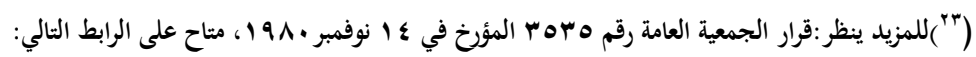

http://www.un.org/en/ga/search/view_doc.asp?symbol=A/RES/35/35\&referer

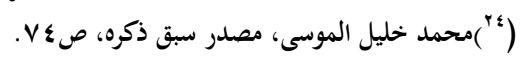

( )

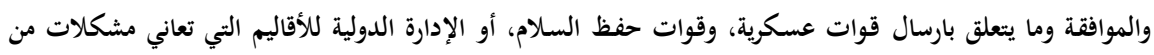

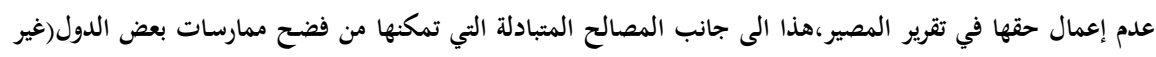

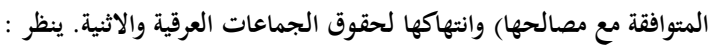


-Sterio, Milena, "On the Right to External Self-Determination: Selfistans, Secession, and the Great Powers Rule", Minnesota Journal of International Law, Vol.19, No.1, 2010, p143.

$\left({ }^{26}\right)$ Brad Simpson, Self-Determination in the Age of Putin, Articles, the magazine foreign policy, 21March, 2014,p2-5.

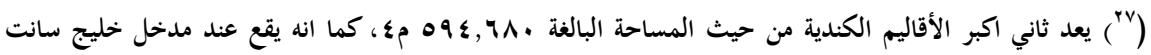

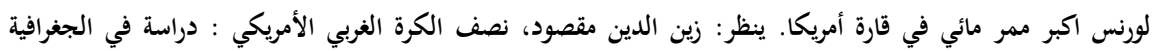

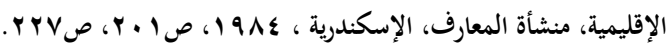

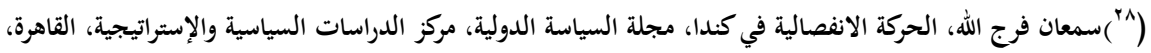

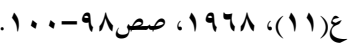

$$
\begin{aligned}
& \text { ( (9q) اصدرت كندا سلسلة قوانين اعطت كيبك امتيازات كحق الاحتفاظ باللغة الفرنسية والسماح بالبقاء على المذهب } \\
& \text { الكاثوليكي، والبقاء على النظم المدنية والإدارية الفرنسية. }
\end{aligned}
$$

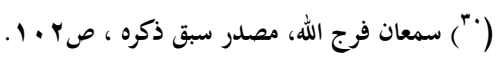

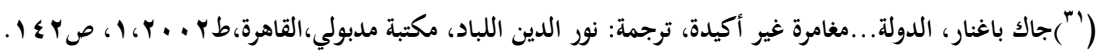

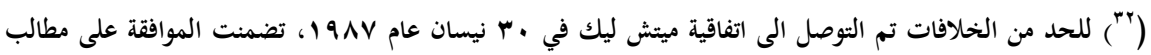

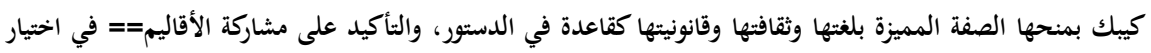

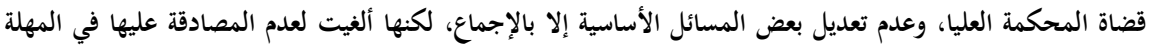

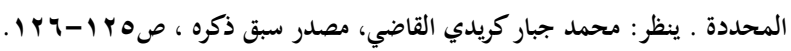

$\left({ }^{33}\right)$ David Cameron, Self-Determination:Canada and Quebec, working Paper on models of Autonomous Rule, Social Science Research Council No. 1, March 2017, p4.http://webarchive.ssrc.org/working-

papers/CPPF_Models\%20of\%20Autonomy_1_Cameron.pdf

$\left.{ }^{34}\right)$ Gary Wilson,Self-determination, Recognition and the Problem of Kosovo, Volume 56, Issue 3 December 2009,pp.455-481.https://doi.org/10.1017/S0165070X09004550

$\left.{ }^{35}\right)$ Catalonia in Spain. For Democratic Coexistence, Gobierno de ESPAÑA, Ministerio de AsuntoExterioresy de Cooperacion, Febrero 2014,p98.

http://www.exteriores.gob.es/Portal/es/SalaDePrensa/Multimedia/Publicaciones/Docu ments/Porlaconvivenci

$\left.{ }^{36}\right)$ Roya M. Hanna, Right to Self-Determination in In Re Secession of Quebec,Maryland Journal of International Law by an authorized administrator of Digital Common, University of Maryland Francis King Carey School of Law, Volume 23, Issue 1,1999, p224.

http://digitalcommons.law.umaryland.edu/cgi/viewcontent.cgi?article=1554\&context $=$ mjil

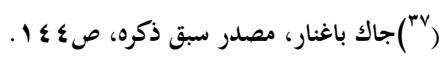

$\left.{ }^{(38}\right)$ Johan D. Van Der Vyver, Self-Determination of the Peoples of Quebec under International Law, College of Law, volume-10-number-1,1992, p9

http://www.law.fsu.edu/docs/default-source/journals/jtpl/previous-issues/volume-10number-1.pdf?sfvrsn=4 
$\left({ }^{39}\right)$ Rainer Knopff Anthony Sayers, Constitutional Politics in Canada, A Global Dialogue on Federalism, Forum of Federations, Canada,2005, volume1,p18. http://www.forumfed.org/library/constitutional-politics-in-canada/

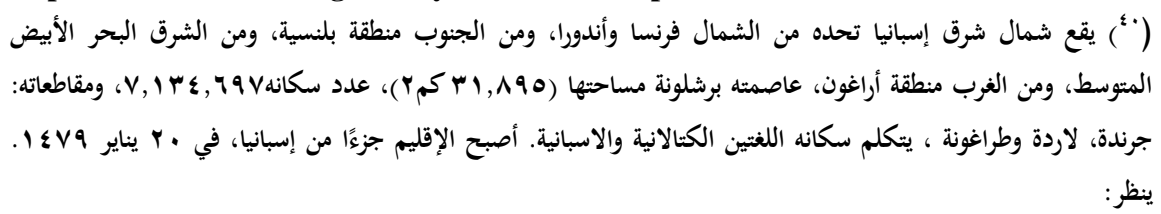

-Catalan, language of Europe, Generalitat de Catalunya, Departament de la Vicepresidència ,Secretaria de PolíticaLingüística, 2006, p4, p27.

http://lengua.gencat.cat/permalink/91192f76-5385-11e4-8f3f-000c29cdf219

$\left({ }^{41}\right)$ Amanda Erickson, Spain vs. Catalonia: Here's what you need to know about the independence showdown, Washington Post, 21 October 2017.

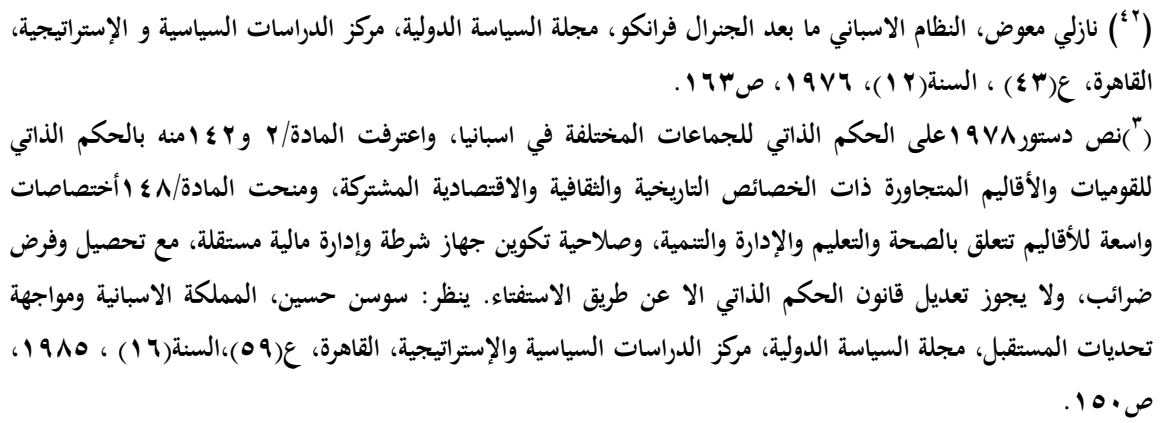

${ }^{(4)}$ Xavier Bernadigil\&Calra Velasco, Spain :A unique model of state Autonomy A global Dialogue on Federalism, Forum of Federations, Canada, 2005,Volum2,pp27-28. http://www.forumfed.org/library/spain-a-unique-model-of-state-autonomy/

$\left({ }^{45}\right)$ Joaquim Sole Vilanova, Joaquim Sole Vilanova, Spain: Redefining Fiscal Equalization and Fiscal Relations, AGlobal Dialogue on Federalism, Forum of Federations, Canada, 2006, Volume4, p32.

http://www.forumfed.org/library/spain-redefining-fiscal-equalization-and-fiscalrelations/

$$
\text { (4) صوت عليه البرلمان الكاتالوني. ينظر الذاتي الذي منحه القانون الاسباني لكاتالونيا أقل من المستوى الممنوح في القانون الأصلي الذي }
$$

-Nicolas Levrat, SandrinaAntunes, Guillaume Tusseau\& Paul Williams, Catalonia's Legitimate Right to Decide Paths to Self-Determintion, report, A Commission of International Experts, 2017, p19.

https://www.unige.ch/gsi/index.php/download_file/view/1450/1154/

(47)Harriet Alexander \& James Badcock, Why does Catalonia want independence from Spain?,the Telegraph news, 10 October 2017.

http://www.telegraph.co.uk/news/0/does-catalonia-want-independence-spain/

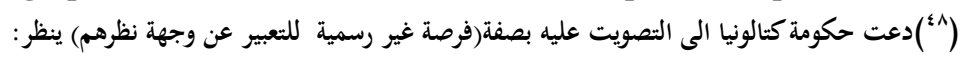

-Nicolas Levrat, SandrinaAntunes, Guillaume Tusseau\& Paul Williams,Op,Cit,p23 
$\left({ }^{49}\right)$ Amanda Erickson, Spain vs. Catalonia: Here's what you need to know about the independence showdown,Op,Cit.

$\left.{ }^{(50}\right)$ Nina Caspersen,The Catalan independence Referendum: Conflicting claims and International Responses, In Report of the International Group of Experts, the Catalan Independence Referendum: an Assessment of the Process of Self Determintion(IRAI),No.01,September2017,p25. https://irai.quebec/wpcontent/uploads/2017/09/IRAI_Rapports-experts Catalogne_EN_final.pdf

${ }^{51}$ Nina Caspersen,Op,Cit,p25.

$\left.{ }^{52}\right)$ Nicolas Levrat, SandrinaAntunes, Guillaume Tusseau \&

PaulWilliams,Op,Cit,p10.

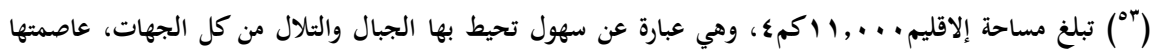

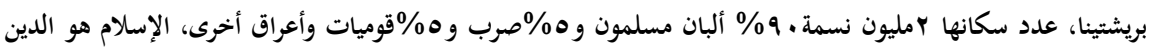

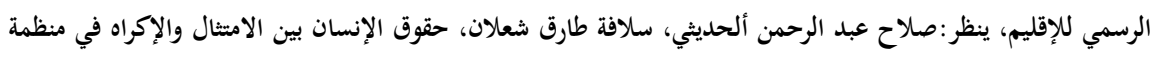

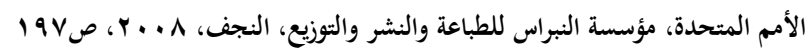

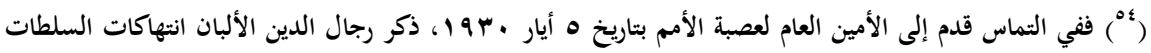

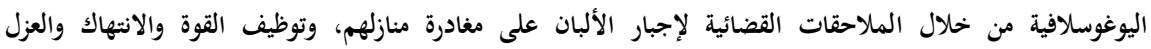

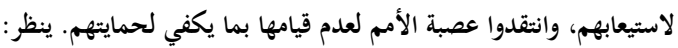

-BesfortRrecaj, The Right to Self-Determination and Statehood: The Kosova Case, Master Thesis, Buffalo Law School, State University of New York,2007, p15. http://law.bepress.com/cgi/viewcontent.cgi?article=7080\&context=expresso

$$
\text { ( ) عن عمليات الطرد والقمع للالبان وأخذ اراضيهم. ينظر : }
$$

- ShkëlzenGashi,The History of Kosovo in the history textbooks of Kosovo, Albania, Serbia, Montenegro and Macedonia,Translated by: Elizabeth Gowing,Report, Institute Alter Habitus, Night Design , 2016, pp77-83.

http://kfos.org/wp-content/uploads/2016/12/ Historia_e_Kosoves_SHG_ENG.pdf

$$
\begin{aligned}
& \text { (") (عماد جاد، التدخل الدولي بين الاعتبارات الإنسانية والأبعاد السياسية، مجلة السياسة الدولية، مركز الاهرام }
\end{aligned}
$$

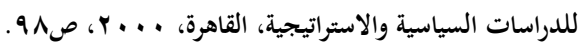

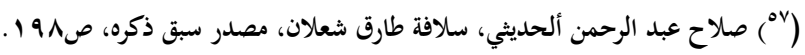

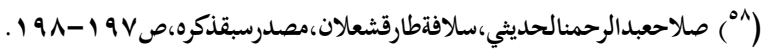

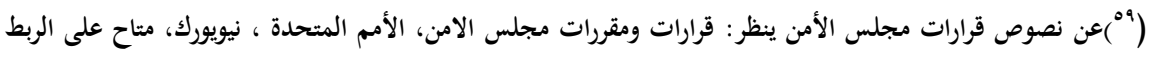

$$
\begin{aligned}
& \text { http://www.un.org التالي: } \\
& \text { (") ("محمد خليل الموسى، استخدام القوة في القانون الدولي المعاصر، دار وائل للنشر والتوزيع، الاردن، } \\
& \text { rov-rorص:r... } \\
& \text { (") (" احمد عبدا لله علي، تطور دور مجلس الامن في حفظ السلم والأمن الدوليين، مؤسسة الفتح للطباعة والنشر، بيروت، } \\
& \text { r...0 } \\
& \text { (") اتخذ الحلف قراره بالثدخل بمعزل عن الأمم المتحدة وفقاً لنظرية التفويض الضمني، كأساس لتدخلها. ينظر : }
\end{aligned}
$$


- مالك عوني، حلف الاطلسي وازمة كوسوفو: حدود القوة وحدود الشرعية، مجلة السياسة الدولية، مركز الدراسات

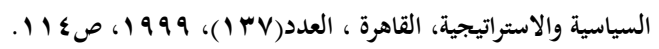

(6)Christian Pippan, The International Court of Justice's Advisory Opinion on Kosovo's declaration of independence: an exercise in the art of silence,Europäisches Journal fürMinderheitenfragen, Printed in Austria, Volume 3, Issue 3-4, December 2010, p146. https://link.springer.com/article/10.1007/s12241-010-0080-x

$\left({ }^{64}\right)$ SprashMehra, Self-Determination- the Kosovo Case ,Article ,Racolblegal , 18 September 2017. http://racolblegal.com/self-determination-the-kosovo-case/

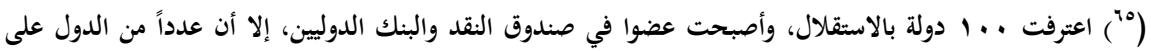

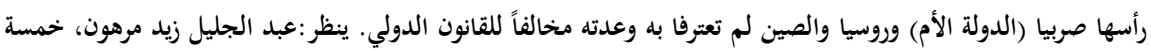

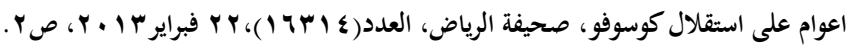

$\left.{ }^{(66}\right)$ Louise Arbour, Self-Determination and Conflict Resolution: From Kosovo to Sudan, International Crisis Group, the Carnegie Council for Ethics inInternational Affairs, 22 September 2010 .

https://www.crisisgroup.org/global/self-determination-and-conflict-resolutionkosovo-sudan

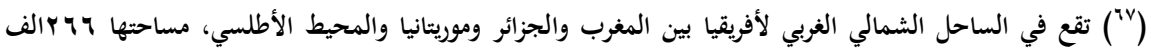

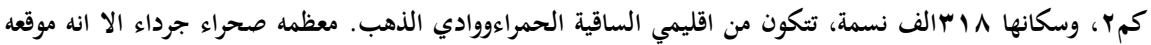

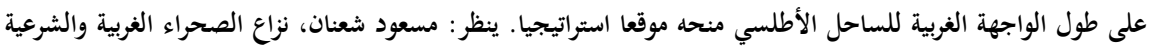

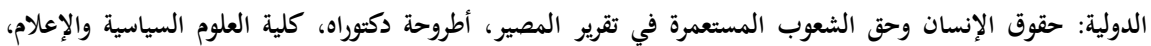

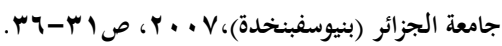

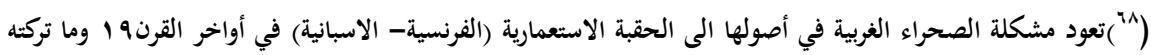

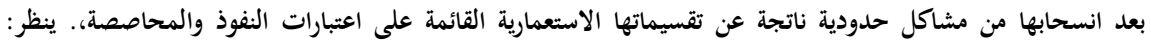

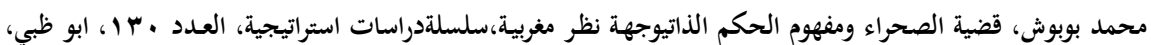

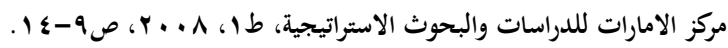

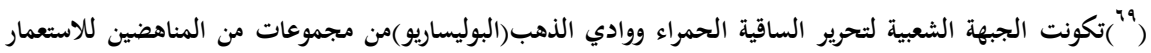

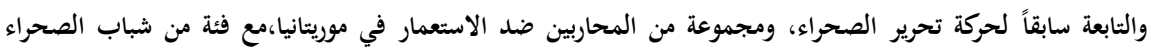

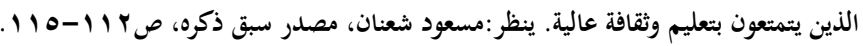

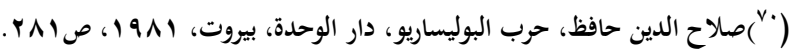

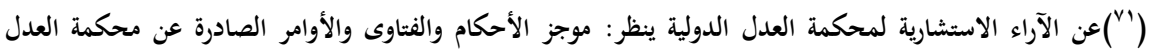

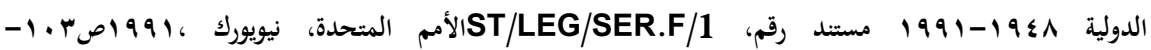
$1 \% 0-1 \cdot v_{6} \mid \mu_{r}$

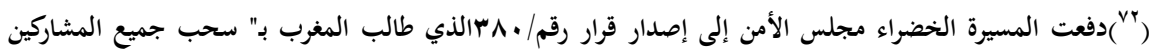

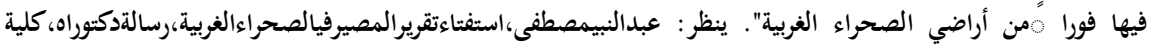

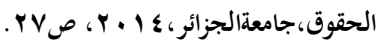




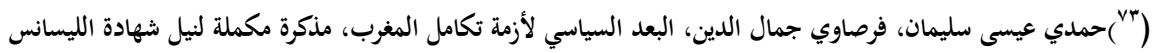

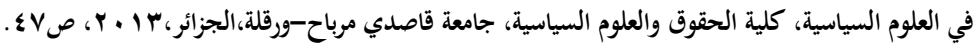

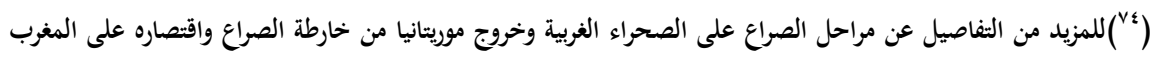

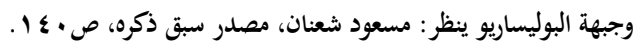

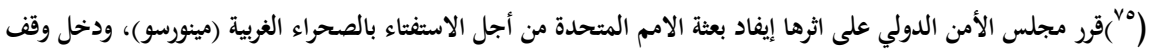

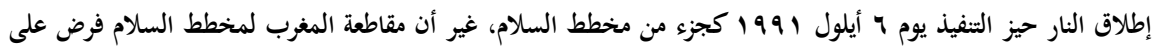

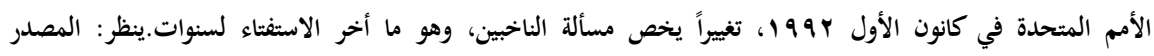

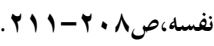

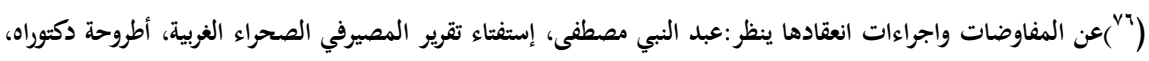

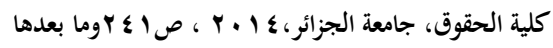

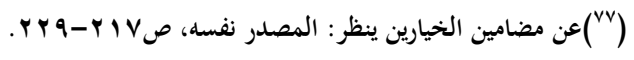

